\title{
A Survey of Transportation Problems
}

\author{
Ocotlán Díaz-Parra, ${ }^{1}$ Jorge A. Ruiz-Vanoye, ${ }^{1}$ Beatriz Bernábe Loranca, ${ }^{2}$ \\ Alejandro Fuentes-Penna, ${ }^{3}$ and Ricardo A. Barrera-Cámara ${ }^{1}$ \\ ${ }^{1}$ Universidad Autónoma del Carmen, Avenida 56 No. 4, Esq. Av. Concordia, Col. Benito Juarez, \\ 24180 Ciudad del Carmen, CAM, Mexico \\ ${ }^{2}$ Benemérita Universidad Autónoma de Puebla, Facultad de Ciencias de la Computación, Ciudad Universitaria, \\ 14 sur y Avenida san Claudio, Edificio 104C, Colonia San Manuel, 72570 Puebla, PUE, Mexico \\ ${ }^{3}$ Universidad Autónoma del Estado de Hidalgo, Av Universidad S/N, Centro, 42780 Tlahuelilpan, HGO, Mexico
}

Correspondence should be addressed to Jorge A. Ruiz-Vanoye; jorge@ruizvanoye.com

Received 30 December 2013; Revised 5 February 2014; Accepted 6 February 2014; Published 27 March 2014

Academic Editor: Francisco Chiclana

Copyright (C) 2014 Ocotlán Díaz-Parra et al. This is an open access article distributed under the Creative Commons Attribution License, which permits unrestricted use, distribution, and reproduction in any medium, provided the original work is properly cited.

\begin{abstract}
This paper aims at being a guide to understand the different types of transportation problems by presenting a survey of mathematical models and algorithms used to solve different types of transportation modes (ship, plane, train, bus, truck, Motorcycle, Cars, and others) by air, water, space, cables, tubes, and road. Some problems are as follows: bus scheduling problem, delivery problem, combining truck trip problem, open vehicle routing problem, helicopter routing problem, truck loading problem, truck dispatching problem, truck routing problem, truck transportation problem, vehicle routing problem and variants, convoy routing problem, railroad blocking problem (RBP), inventory routing problem (IRP), air traffic flow management problem (TFMP), cash transportation vehicle routing problem, and so forth.
\end{abstract}

\section{Introduction}

The Transportation Problems (TP) is the generic name given to a whole class of problems in which the transportation is necessary. The general parameters of TP are as follows.

(A) Resources. The resources are those elements that can be transported from sources to destinations. Examples of discrete resources are goods, machines, tools, people, cargo; continuous resources include energy, liquids, and money.

(B) Locations. The locations are points of supply, recollection, depot, nodes, railway stations, bus stations, loading port, seaports, airports, refuelling depots, or school.

(C) Transportation modes. The transportation modes are the form of transporting some resources to locations. The transportation modes use water, space, air, road, rail, and cable. The form of transport has different infrastructure, capacity, times, activities, and regulations. Example of transportation modes are ship, aircraft, truck, train, pipeline, motorcycle, and others.

This paper aims to be a guide to understand the Transportation Problems (TP) by presenting a survey of the characteristics, the algorithms used to solve the problems, and the differences of the variants of the Transportation problems. Section 2 presents the classification and the general parameters of the Transportation Problems, Section 3 the variants of the Transportation Problems, and Section 4 the algorithms used to solve the Transportation Problems, and the last section presents the conclusions.

\section{Transportation Problems}

The transportation problems are to minimize the cost of carrying resources, goods, or people from one location (often know as sources) to another location (often know as destinations) using diverse types of transportation modes (ship, aircraft, truck, train, pipeline, motorcycle and others) by air, 
water, road, aerospace, tube, and cable with some restrictions as capacity and time windows. The types of transportation problems are as follows.

2.1. Maritime Transportation. The maritime transportation carries resources over long distances from locations to other locations using maritime routes composed of oceans, coasts, seas, lakes, rivers, and canals of ships, or similar routes.

Resources. Bulk cargo (oil, coal, iron ore, grains, bauxite/alumina, phosphate, dry or liquid not packet); breakbulk cargo (bags, boxes, drums, all general cargoes that have been packaged); passenger vessels (passenger ferries, cruise ships); bulk carriers (liquid bulk vessels, dry bulk vessels, largest tankers of liquefied natural gas technology enabled); general cargo (vessels designed to carry nonbulk cargoes); Roll-on/Roll-off (RORO vessels, cars, trucks, and trains to be loaded directly on board); shrimp and seafood, hazardous materials; military-owned transportation resources; and goods (nonperishable goods, final manufactured goods, processed food, produce, livestock, intermediate goods, processed and raw materials).

Locations. Fishing port, warm water port, sea port, cruise port, cargo port, cruise home port, port of call, cargo ports, and oil platform.

Transportation Mode. Bulk carriers, container ships, tankers, reefer ships, Roll-on/Roll-off ships, coastal trading vessels, ferries, cruise ships, ocean liner, cable layer, tugboat, dredger, barge, general cargo ship, submarines, sailboat, jet boat, fishing vessels, service/supply vessels, barges, research ships, dredgers, and naval vessels.

2.2. Air Transportation. The air transportation carries resources over long, medium, and short distances from locations to other locations using air routes by aircrafts, charter flights, planes or others.

Resources. Military-owned transportation resources, passengers, air taxi service, goods, supplies and equipment, mail, troops, and others.

Locations. Airport terminals, heliport, helipads, helistop, Helideck and Helispot, and area of military operations.

Transportation Mode. Fixed-wining aircraft, airplane, gyroplane, recreational aircraft, military cargo aircraft, helicopters, zeppelins, personal air transportation with jet packs and blimps, military transport helicopters, tactical and strategic airlift, air ambulance, and aerial refuelling.

2.3. Land Transportation. The land transportation carries resources over long, medium, and short distances from locations to other locations using the road routes by vehicle or similar means of land transportation.

Resources. Military-owned transportation resources, goods, people, hazardous materials, waste, or money.
Locations. Pizza restaurant, post office, university, schools, gas stations, warehouse, stores, markets, fish market, dump, bottling plants, malls, depots, houses, Landfill, incineration plant, waste container, banks, and others.

Transportation Mode. Buses; trucks; motorcycles; bicycles; cars and pickups; box trucks and dock highs; cargo and sprinter vans; less than truck Load (LTL); full truck load (FTL); flatbeds; reefers (refrigerated units); longer combination vehicles (LCV) with double semitrailer, recovery vehicle, scooters, and pedestrians; main battle tank; infantry fighting vehicles; armored personnel carriers; light armored vehicles; self-propelled artillery and anti-Air mine protected vehicles; combat engineering vehicles; prime movers and trucks; unmanned combat vehicles; military robot; joint light tactical vehicle (JLTV), utility vehicle, refrigerator truck, landfill compaction vehicle, garbage truck, waste collection vehicle; armored cash transport car; and security van.

2.4. Rail Transportation. Rail transport carries resources over long, medium, and short distances by way of wheeled vehicles running on rail track or railway.

Resources. Military-owned transportation resources, goods, passenger, containers, and bulks.

Locations. Stations, transit centre locations, park and ride locations, railway station, railroad station, goods stations, large passenger stations, smaller stations, early stations, central stations, railway platform (bay platform, side platform, island platform), metro station, train station, tram stop, station facilities, terminal, interchange station, tunnel stations, metro depot, maintenance depot, and light rail depot.

Transportation Mode. Trains, metro, subway, vactrain, magnetic levitation train, ground effect train, U-Bahn and SBahn, intercity trains, intercity rail, high-speed rail, high speed train, locomotive, pacer (train), freight car, goods train, railway passenger car, coach passenger car, intermodal freight transport, refrigerated railroad cars, light rail vehicles, suburban railway, urban railway, rapid transit, underground railway, elevated railway, metropolitan railway, carbody, ballast tamping machine, long welded rail cars, cleaning trains, concreting trains, rail grinders, ballast tamping machines, track recording cars, and rail grinders.

2.5. Space Transportation. Space transportation carries resources from locations to other locations by suborbital and orbital flights in the upper atmosphere and the space by Hall Electric propulsion or similar.

Resources. Military-owned transportation resources, cargo or passengers, personnel, fuel (LH2), oxydizer (LOX), and propellants (LOX and $\mathrm{LH} 2$ at given mixture ratio).

Locations. Earth spaceport (ES), Low Earth Orbit (LEO), Geostationary Earth Orbit (GEO), Lagrange Point L1 (L1), Low Lunar Orbit (LUO), Lunar SpacePort (LUS), Lagrange Point L2 (L2), Planetary escape mission (PLA), Mars Spaceport 
(MAS), Space Operations Center, Lunar Service Center, Lunar Propellant Production Facility, and others.

Transportation Mode. Rocket-powered aircraft, nuclear powered aircraft, spacecraft, space shuttle, space, space planes, rockets, missiles, and advanced Hall electric propulsion, crew exploration vehicle (CEV), automated transfer vehicle (ATV), evolved expendable launch (EELV), National Aerospace Plane (NASP), transatmospheric vehicle (TAV), orbital space plane, next generation launch technology, winged shuttle (WSLEO), expendable interorbital ferry vehicle (EIOFV), reusable interorbital ferry vehicle (RIOFV), and spaceship.

2.6. Pipeline and Cable Transportation. Pipeline and cable transportation carries resources from locations to other locations by pipe and vehicles pulled by cables.

Resources. Water, energy, electricity, petroleum products, telecommunications, chemicals, slurry coal, natural gas, sewage, beer, biofuels (ethanol and biobutanol), hydrogen, skiers, and passenger lift.

Locations. Residential and commercial areas, treatment plant, processing facility, gas stations, pump stations, terminals, tanks, storage facilities, partial delivery stations, inlet station, injection station, block valve station, regulator station, final delivery station, floors (levels, decks) of a building, vessel, or other structures.

Transportation Mode. Pipelines (gathering pipelines, transportation pipelines, distribution pipelines), ducts, oil pipelines, gas pipeline, transmission lines, electrical substations, pole-mounted transformed, generation stations, distribution systems, electricity transmission system, tubes, aerial lifts (aerial tramway, chairlift, funitel, gondola lift, ski lift), surface cable transportation (cable car, cable ferry, funicular, surface lift), and vertical transportation (Elevator).

2.7. Intermodal Transportation. Intermodal transportation carries resources from locations to other locations using maritime, air, road, rail, cable, tube, and/or space routes by ships or similar, aircraft or similar, vehicle or similar, trains or similar, Hall Electric propulsion or similar, pipe and/or vehicles pulled by cables.

\section{Variants of the Transportation Problems}

3.1. Maritime Transportation Problems. In the specialized literature there exist various variants of the Maritime Transportation Problems. The main variants of the Maritime Transportation Problems are RoRo ship stowage problem (RSSP) [1]; ship routing problem (SRP) [2, 3]; ship routing problem of tramp shipping (SRPTP) [2]; inventory constrained maritime routing and scheduling problem for multicommodity liquid bulk [4]; vessel fleet scheduling/allocation $[5,6]$; cargo routing problem [4]; maritime inventory ship routing problem [7]; oil-tanker routing and scheduling problem $[8,9]$; maritime oil transportation problem [10]; industrial ship scheduling problem [7]; industrial ship scheduling problem with fixed cargo sizes [7]; tramp ship scheduling problem [7]; single product inventory ship routing problem [7]; multiple product inventory ship routing problem [7]; tramp ship routing and scheduling problem with speed optimization [11]; and maritime platform transport problem of solid, special and dangerous waste [12].

The RoRo ship stowage problem (RSSP) [1] to decide (which optional cargoes to carry, how stow all cargoes on board the ship, all long-term contracts are fulfilled) upon a deck configuration with respect of the height. The objective is to maximize the sum of revenue from optional cargoes minus penalty costs incurred when having to move cargoes. The mathematical model of RSSP [1] is formed by (1)-(18):

$$
\begin{gathered}
\max \sum_{c \in C_{0}} R_{c}^{F} Z c-\sum_{c \in C} \sum_{c^{\prime} \in C c} \sum_{d \in D} \sum_{l \in L} C_{c}^{M} W_{d l c c^{\prime}} \\
C_{c}^{L} \cdot y_{d l p c}-L_{d} \cdot x_{d l p c} \leq 0, \quad d \in D, l \in L, c \in C, p \in P c,
\end{gathered}
$$

$C_{c}^{H} \cdot x_{d l p c}-\left(h_{d+1}-h_{d}\right) \leq 0, \quad d \in D, l \in L, c \in C, p \in P c$,

$$
\begin{gathered}
C_{c}^{W} \cdot x_{d l p c}-v_{d l} \leq 0, \quad d \in D, l \in L, c \in C, p \in P c, \\
y_{d, l, p+1, c}-y_{d l p c}=0, \quad p \in P c \backslash\left\{P_{c}^{U}-1\right\},|P c| \geq 2, \\
\sum_{l \in L} V_{d l}=W_{d}, \quad d \in D, \\
\sum_{d \in D} \sum_{l \in L} y_{d l p c}=N c, \quad c \in C_{M}, p \in P c, \\
\sum_{d \in D} \sum_{l \in L} y_{d l p c}=N c Z c, \quad c \in C_{0}, p \in P c, \\
\sum_{c \in C} C_{c}^{L} \cdot y_{d l p c} \leq L_{d}, \quad d \in D, l \in L, p \in P,
\end{gathered}
$$$$
-T^{\mathrm{MAX}} \leq \sum_{c \in \mathrm{C}} \sum_{d \in D} \sum_{l \in L} C_{c}^{V} \cdot y_{d l p c} \cdot \bar{X}_{d l} \leq T^{\mathrm{MAX}}, \quad p \in P,
$$$$
W^{S} Y^{S}+\sum_{c \in C} \sum_{d \in D} \sum_{l \in L} C_{c}^{V} y_{d l p c} \bar{Y}_{d}
$$$$
\leq\left(W^{S}+\sum_{c \in C} \sum_{d \in D} \sum_{l \in L} C_{c}^{V} y_{d l p c}\right) Y^{\mathrm{MAX}}, \quad p \in P,
$$

$$
z_{d l, P_{c}^{L}, c^{\prime}} \leq 1+w_{d l c c^{\prime}}, \quad d \in D, l \in L, c \in C, c^{\prime} \in C c,
$$

$$
\begin{gathered}
D_{d}^{L} \leq h_{d} \leq D_{d}^{U}, \quad i \in D^{R}, \\
v_{d l} \geq 0, \quad d \in D, \quad l \in L, \\
w_{d l c c^{\prime}} \in\{0,1\}, \quad d \in D, l \in L, c \in C, c^{\prime} \in C c, \\
w_{d l p c} \in\{0,1\}, \quad d \in D, l \in L, c \in C, p \in P c, \\
z_{c} \in\{0,1\}, \quad c \in C,
\end{gathered}
$$

$y_{d l p c} \geq 0$ and integer, $d \in D, l \in L, c \in C, p \in P c$, 
where $C$ is the set of all cargoes, $C_{M}$ is the set of all mandatory cargoes, $C o$ is the set of all optional cargoes, $D$ is the set of all decks, $L$ is the set of all potential lanes on each decks, $P$ is the set of all ports (except the last port on the route), $P c$ is the set of ports from loading port of cargo $c$ to the port before the unloading port of cargo $c, C c$ is the set of cargoes $c^{\prime}, W_{d}$ is the width of deck $d, L_{d}$ is the length of deck $d, C_{c}^{L}$ is the length of one vehicle in cargo $c, C_{c}^{W}$ is the width of one vehicle in cargo $c, C_{c}^{H}$ is the height of one vehicle in cargo $c, P_{c}^{L}$ is the loading port of cargo $c, P_{c}^{U}$ is the unloading port of cargo $c, D_{d}^{L}$ is the lower bound for where deck $d$ can be placed, $D_{d}^{U}$ is the upper bound for where deck $d$ can be placed, $R_{c}^{F}$ is the revenue for transporting optional cargo $c, N c$ is the number of vehicles in cargo $c, C_{c}^{M}$ is the cost incurred if cargo $c$ needs to be moved, $T^{\mathrm{MAX}}$ is the maximum allowable torque on the ship from the cargo, $Y^{\mathrm{MAX}}$ is the highest allowable center of gravity of the laden ship, $C_{c}^{V}$ is the weight of one vehicle from $\operatorname{cargo} c$, WS is the lightweight of the ship, $Y^{S}$ is the vertical distance from the ship's bottom deck to its center of gravity when empty, $\bar{X}_{d l}$ : approximated horizontal distance of lane $l$ on deck $d$ from the ship's center of gravity, $\bar{Y}_{d}$ is the approximated vertical distance of deck $d$ from the ship's bottom deck, $c$ is the cargo, $d$ is the deck, $l$ is the lane, and $p$ is the port.

In (1) the objective is to maximize the sum of revenue from optional cargoes minus penalty costs incurred when having to move cargoes. Equation (2) links the binary indicator variables $x_{d l p c}$ for if lane $l$ on deck $d$ is used from port $p$ to $p+1$ by cargo $c$, to the integer variables $y_{d l p c}$ for how many vehicles from cargo $c$ that are stowed in lane $l$ on deck $d$ from port $p$ to $p+1$. Equation (3) ensures that there is enough vertical space on the deck where the cargoes are placed. Equation (4) shows the sufficient width of the lanes. Equation (5) makes sure that once a cargo has been placed, it remains unmoved until it is unloaded. In (6), the partitions of decks into lanes are restricted. Equations (7) and (8) link the integer variables $y_{d l p c}$ for how many vehicles from cargo $c$, that is, stowed in lane $l$ on deck $d$ from port $p$ to $p+1$, to the number of vehicles from cargo $c$, that is, carried, for respectively mandatory and optional cargoes. Equation (9) ensures that the length of a lane is not violated by the vehicles stowed in that lane. Equations (10) and (11) are restrictions on ship stability calculations and involve nonlinear equations. Equation (10) imposes that the torque from the cargo on the ship should be within the allowable limit to avoid rolling. The constants view the $\bar{X}_{d l}$ are approximations of the horizontal distance of a lane to the center of the ship, with negative values indicating a possible tilt to the port side and positive values indicating a tilt to the starboard side. Equation (11) ensures that the maximum allowable vertical distance $Y^{\mathrm{MAX}}$ from the ship's bottom deck to the ship's centre of gravity when loaded is not exceeded. When vehicles from cargo $c$ are loaded in front of vehicles from cargo $c^{\prime}$ and cargo $c^{\prime}$ is unloaded before cargo $c$, there is an inconvenience as vehicles from cargo $c$ must be moved out of the way. Equation (12) makes sure that a corresponding penalty is added to the objective function. Equation (13) provided upper and lower bounds on the deck heights. Equation (14) ensured the nonnegativity of lane width. Equations (15), (16), and (18) make sure that the variables $w_{d l c}, x_{d l p c}$, and $z_{c}$ take binary values. And (18) imposes nonnegativity and integrality on the number of vehicles carried in each lane.

3.2. Air Transportation Problems. In the specialized literature there exist various variants of the Air Transportation Problems. The main variants of the Air Transportation Problems are air traffic flow management problem (TFMP) [13], multiairport ground holding problem (MAGHP) [14, 15], air traffic flow management rerouting problem (tfmrp) [16], helicopter routing problem (HRP) [17], airline crew scheduling problem [18], and oil platform transport problem [19].

The general problem of Air Transportation is represented in the mathematical model described by Li et al. [20, 21], which presents an objective that is to minimize the overall total cost which consists of the total transportation cost of the orders allocated to normal flight capacity, the total transportation cost for the orders allocated to special flight capacity, and the total delivery earliness tardiness penalties cost. The mathematical programming formulation of the model is shown as follows:

$$
\begin{aligned}
& \min \sum_{i=1}^{N} \sum_{f=1}^{F} N C_{f} X_{i f}+\sum_{i=1}^{N} \sum_{f=1}^{F} S C_{f} Y_{i f} \\
& +\sum_{i=1}^{N} \sum_{f=1}^{F} \alpha_{i} * \max \left(0, d_{i}-A_{f}\right) *\left(X_{i f}+Y_{i f}\right) \\
& +\sum_{i=1}^{N} \sum_{f=1}^{F} \beta_{i} * \max \left(0, A_{f}-d_{i}\right) *\left(X_{i f}+Y_{i f}\right), \\
& L N * X_{i f} *\left|\operatorname{Des}_{i}-\operatorname{des}_{f}\right|<1, \quad i=1, \ldots, N ; f=1, \ldots, F, \\
& L N * Y_{i f} *\left|\operatorname{Des}_{i}-\operatorname{des}_{f}\right|<1, \quad i=1, \ldots, N ; f=1, \ldots, F,
\end{aligned}
$$

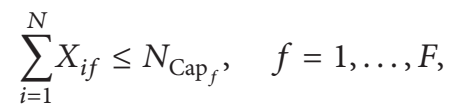

$$
\begin{aligned}
& \sum_{i=1}^{N} Y_{i f} \leq S_{\text {Cap }_{f}}, \quad f=1, \ldots, F, \\
& \sum_{f=1}^{F}\left(X_{i f}+Y_{i f}\right)=Q_{i}, \quad i=1, \ldots, N, \\
& \sum_{i=1}^{N}\left(\frac{\max \left(0,\left(\sum_{f^{\prime}=1}^{f} X_{i f^{\prime}}+Y_{i f^{\prime}}\right)-0.5\right)}{\left(\sum_{f^{\prime}=1}^{f} X_{i f^{\prime}}+Y_{i f^{\prime}}\right)-0.5}\right) p_{i} \\
& \leq D_{f}, \quad f=1, \ldots, F, \\
& X_{i f}, Y_{i f}=\text { Non-negative Integer Variables, }
\end{aligned}
$$

where $i, i^{\prime}$, and $j$ are the order or job index, $i=1,2, \ldots, N ; f$ or $f^{\prime}$ is the flight index, $f=1,2, \ldots, F ; k$ is the destination 
index, $k=1,2, \ldots, K ; D_{f}$ is the departure time of flight $f$ at the local airport; $A f$ is the arrival time of flight $f$ at the destination; $N C_{f}$ is the transportation cost for per unit product when allocated to normal capacity area of flight $f$; $S C_{f}$ is the transportation cost for per unit product when allocated to special capacity area of flight $f ; N_{\mathrm{Cap}_{f}}$ is the available normal capacity of flight $f ; S_{\mathrm{Cap}_{f}}$ is the available special capacity of flight $f ; Q_{i}$ is the quantity of order $i ; \alpha_{i}$ is the delivery earliness penalty cost (/unit/h) of order $i$; $\beta_{i}$ is the delivery tardiness penalty cost (/unit/h) of order $i$; $d_{i}$ is the due date of order $i ; X_{i f}$ is the quantity of the portion of order $i$ allocated to flight $f^{\prime} s$ normal capacity area; $Y_{i f}$ is the quantity of the portion of order $i$ allocated to flight $f^{\prime} s$ special capacity area; Des $i$ is the order $i^{\prime} s$ destination; $\operatorname{Des}_{f}$ is the flight $f^{\prime} s$ destination; $L N$ is a large positive number; $p_{i}$ is the processing time of order $i$. The decision variables $\left(X_{i f}\right.$, $Y_{i f}$, and $Z_{i f}$ ) are nonnegative integer.

The objective of (19) is to minimize total cost which consists of transportation cost of orders allocated into normal flight capacity, transportation cost of orders allocated into special flight capacity, the delivery earliness penalty costs of orders, and the delivery tardiness penalty costs of orders. Equations (20) and (21) ensure that if order $i$ and flight $f$ have different destination, order $i$ cannot be allocated to flight $f$. Equation (22) ensures that the quantity of the portion of order $i$ allocated into flight $f$ consists of quantities of the portion of order $i$ allocated into normal capacity area of flight $f$ and the portion of order $i$ allocated to special capacity area of flight $f$. Equation (23) ensures that the normal capacity of flight $f$ is not exceeded. Equation (24) ensures that the special capacity of flight $f$ is not exceeded. Equation (25) ensures that order $i$ is completely allocated. Equation (26) ensures that allocated orders do not exceed production capacity. It ensures that allocated quantity can be supplied by sufficient assembly capacity.

3.3. Land Transportation Problems. In the specialized literature there exist various variants of the Land Transportation Problems. The main variants of the Land Transportation Problems are bus terminal location problem (BTLP) [22], convoy routing problem (CRP) [23], inventory routing problem (IRP) [24], inventory routing problem with time windows (IRPTW) [25], school bus routing problem (SBRP) [26], tour planning problem (TPP) [27], truck and trailer routing problem (TTRP) [28], vehicle departure time optimization (VDO) problem [29], vehicle routing problem with production and demand calendars (VRPPDC) [30], bus terminal location problem (BTLP) [22], bus scheduling problem [31], delivery problem [32], combining truck trip problem [33], open vehicle routing problem [34], transport problem [35], truck loading problem [36], truck dispatching problem [37], convoy routing problem [23], multiperiod petrol station replenishment problem [38], petrol station replenishment problem [39], vehicle routing problem [40], capacitated vehicle routing problem (CPRV) [40], multiple depot vehicle routing problem (MDVRP) [40], periodic vehicle routing problem (PVRP) [40], split delivery vehicle routing problem (SDVRP) [40], stochastic vehicle routing problem (SVRP) [40], vehicle routing problem with backhauls (VRPB) [40], vehicle routing problem with pick-up and delivering (VRPPD) [40], vehicle routing problem with satellite facilities [40], vehicle routing problem with time windows (VRPTW) [40], waste transport problem (WTP) [41], cash transportation vehicle routing problem [42], team orienteering problem [43], military transport planning (MTP) [44], petrol station replenishment problem with time windows [45].

The school bus routing problem (SBRP) is a significant problem in the management of school bus fleet for the transportation of students; each student must be assigned to a particular bus which must be routed in an efficient manner to pick up (or return home) each of these students [26]. The characteristics of SBRP [46] are number of schools (single or multiple), surrounding services (urban or rural), problem scope (morning, afternoon, both), mixed Load (allowed or no allowed), special-education students (considered or not considered), fleet mix (homogeneous fleet or heterogeneous fleet), objectives (number of buses used, total bus travel distance or time, total students riding distance or time, student walking distance, load balancing, maximum route length, Child's time loss), constraints (vehicle capacity, maximum riding time, school time windows, maximum walking time or distance, earliest pick-up time, minimum student number to create a route). The mathematical model of SBRP [47] is formed by (27)-(34):

$$
\begin{gathered}
\min z=\sum_{i=0}^{n} \sum_{j=0}^{n} \sum_{k=1}^{M} C_{i j} X_{i j k}, \\
\sum_{k=1}^{M} \sum_{j=0}^{n} X_{i j k}=1, \quad i=1,2, \ldots, n, \\
\sum_{k=1}^{M} \sum_{i=0}^{n} X_{i j k}=1, \quad j=1,2, \ldots, n, \\
\sum_{k=1}^{M} \sum_{j=0}^{n} X_{0 j k}=\sum_{k=1}^{M} \sum_{i=0}^{n} X_{i 0 k}=M, \\
\sum_{j=0}^{n} X_{i j k}=\sum_{j=0}^{n} X_{j i k} ; \quad i=1,2, \ldots, n ; k=1,2, \ldots, M, \\
U_{i k}+U_{j k}+(n-m+1) X_{i j k} \leq(n-M) ; \\
1 \leq i, j \leq n, i \neq j, k=1,2, \ldots, M, \\
\sum_{i=0}^{n} \sum_{j=0}^{n} X_{i j k} q_{i} \leq Q ; \quad k=1,2, \ldots, M, \\
\sum_{i=1}^{n} \sum_{j=0}^{n} X_{i j k} t_{i j} \leq \tau ; \quad k=1,2, \ldots M .
\end{gathered}
$$

School buses are centrally located and have to collect waiting students at $n$ pick-up points and to drive them to school. The number of students that wait in pickup point $i$ is $q_{i},\left(q_{i}>0\right.$, $i=1,2, \ldots, n)$. The capacity of each bus is limited to $Q$ 
students $\left(q_{i} \leq Q\right)$. The objective function of the School Bus Problem is composed of two costs: (a) cost incurred by the number of buses used, (b) driving cost (fuel, maintenance, drivers salary, and others), subject to operational constraints, Costs (a) or (b) have to be minimized. For a given $M$ of buses, let $X_{i j k}, i, j=0,1,2, \ldots, n, k=1,2, \ldots, M$ be variables that attain the value 1 if pickup points $i$ and $j$ are visited by the $k$ th bus and pickup point $j$ is visited directly after $i$. Otherwise, $X_{i j k}$ is 0 . Let $U_{i k}, i=0,1, \ldots, n, k=1,2, \ldots, M$ be variables that may attain any value. The objective of the SBRP is to find variables $X_{i j k}$ and $U_{i k}$ that minimize $z$. Where $C_{i j}=$ cost of driving from point $i$ to point $j, C_{i j}$ is a function of the distance between $i$ and $j$ and the driving time, $C_{i j}=\left\{\begin{array}{l}C_{i j} \forall i, j, i \neq j, \\ \infty\end{array} \forall i=j, t_{i j}\right.$ $=$ driving time from point $i$ to point $j, q_{i}=$ a quantity to be loaded (or unloaded) at $i, k=$ set of constraints characterized by the nature of the problem, where $k=(1,2, \ldots, K) \in K$. The three-dimensional assignment problem given in ((28), (29), (30), (31), and (32)) could be transformed into a regular assignment problem by duplicating $M-1$ times the row and column corresponding to city 0 and obtaining an assignment problem with dimensions $(n+M)$ by $(n+M)$. Constraints ensure the formation of exactly $M$ tours, where each one passes through the school. The restriction of capacity is in (33) and the constraint of time is in (34).

SBRP is formulated as mixed integer programming or nonlinear mixed integer programming models. The researchers are often not used to directly solve the problems; they use a relaxation of the problem to solve it. School bus schedules are important because they reduce costs to the universities or schools and bring added value to the students to have a quality transport.

3.4. Rail Transportation Problems. In the specialized literature there exist various variants of the Rail Transportation Problems. The main variants of the Rail Transportation Problems are train formation problem (tfp) [48], locomotive routing problem [49], tour planning problem by rail (tpp) [50], rolling stock problem ( $\mathrm{rsp}$ ) [51], yard location problem [52], and train dispatching problem [53].

Train dispatching transportation problem, train meetand-pass problem, or train timetabling problem is the process of handling a given set of desired train operating schedules and merging these requests as best as possible to a valid timetable [53]:

$$
\begin{gathered}
\max w^{T} x, \\
\sum_{i} x_{b t}^{i} \leq 1, \quad \forall b \in B, t=1, \ldots, T, \\
x^{i} \in T^{i}, \quad \forall i \in I,
\end{gathered}
$$

Equations (36) and (37) are the track capacity constraint, these equations ensure ensures that no two trains are scheduled that occupy the block $b \in B$ at the same moment $t$. Each binary variable $x_{b t}^{i}$ takes the value of one if and only if the train $i$ occupies the block $b$. The set $T$ contains all vectors that result in technically and logistically feasible schedules for the train $i$.
3.5. Space Transportation Problems. In the specialized literature there exist various variants of the Space Transportation Problems. The main variants of the Space Transportation Problems are generalized location routing problem with space exploration or generalized location routing problem with profits (GLRPPs) [54], Earth-Moon supply chain problem [55], interplanetary transfer between halo orbits [56], and Hill's restricted three-body problem (Hill's R3BP) [57].

The Earth-Moon supply chain problem [55] considers the problem of delivering cargo units of water from low Earth orbit to lunar orbit and the lunar surface. The formulation requires that the architectural characteristics of the vehicle used to transport the packages to the destinations and the paths the vehicles travel are to be determined concurrently. The problem is solved using both traditional design optimization methods and a concurrent design optimization method:

$$
\begin{aligned}
& \min J=\sum_{i=1}^{n} \sum_{j=i}^{n} \sum_{k=j}^{n} n_{i j k} m_{w i j k} \\
& \sum_{j=1}^{n} \sum_{k=j}^{n} x_{1 j k}=s(1) \\
& \sum_{i=1}^{n} \sum_{j=i}^{k} x_{i j k}=d(k), \quad \forall k=2, \ldots, n \\
& \sum_{k=j}^{n} x_{i j k} \leq \sum_{k=j}^{n} C_{i j k} n_{i j k}, \quad \forall j, \\
& x_{i j k} \leq C_{i j k} n_{i j k}, \quad \forall i, j, k j \neq k, \\
& x_{i j j} \leq \sum_{k=j}^{n} c_{i j k} n_{i j k}, \quad \forall i, j, \\
& 1 \leq \sum_{i=1}^{m} S_{i} \leq m, \quad S_{i} \in\{0,1\} \\
& f_{i+1}-f_{i} \leq p S_{i}, \quad \forall 1, \ldots, m-1, \\
& \frac{m_{p l}}{m_{0}}=\prod_{i=1}^{N_{\text {stage }}}\left(1+\alpha_{i}\right) \exp \left(\frac{-\Delta V_{i}}{I_{s p_{i}} g_{0}}\right)-\alpha_{i} ; \quad N_{\text {stage }}=\sum_{i=1}^{m} S_{i}, \\
& m_{w}=m_{p l} C\left(\frac{m_{0}}{m_{p l}}-1\right)
\end{aligned}
$$

where $(i, j, k)$ is the transfer starting at node $i$ traveling to node $j$ and terminating at node $k, n_{i j k}$ is the number of vehicles on route $(i j k), C_{i j k}$ is the capacity of vehicle on route $(i, j, k), m_{0 i j k}$ is the vehicle initial mass, $m_{w 1 k}$ is the vehicle wet mass, $x_{i j k}$ is the number of packets that leave node $i$ equal to the supply at node $i(s(i))$, and $\Delta V$ is the velocity change.

Equation (38) defines the main objective. The main objective of the system is to minimize the initial mass of the 
transportation system architecture. The $n_{i j k}$ is the number of vehicles that start at node $i$, travel to node $j$, and then terminate at node $k$ and $m_{0 i j k}$ is the initial mass of a vehicle on route $(i, j, k)$. The initial vehicle mass $\left(m_{0 i j k}\right)$ is determined by the vehicle capacity for each route $C_{i j k}$ and the actual initial mass is the wet mass $\left(m_{w i j k}\right)$ plus the amount of payload carried on that vehicle. Each route carries $x_{i j k}$ packages that each weighs $m_{p l}$. For each route, the initial mass is defined as $n_{i j k m} w_{i j k}+x_{i j k} m_{p l}$ and this is summed over all routes. The summation of $x_{i j k}$ over all routes is simply the amount of supply, which is a constant. Equation (39) contains a restriction of the network subsystem that determines the actual package flows from Low Earth Orbit (LEO) to the destination nodes. To ensure a feasible package flow, we must define the supply, demand, and capacity constraints for the space network. The supply constraints ensure that the number of packages $\left(x_{i j k}\right)$ that leave node $i$ is equal to the supply at node $i(s(i))$. Equation (40) ensures that the number of packages that arrive at node $k$ is equal to the demand of node $k(d(k))$. Equation (41) ensures that the vehicle has enough capacity to accommodate the packages. Equations (42) and (43) contain the upper bound on the number of packages on each route. Equation (44) defines a binary decision variable, $S_{i}$, which is equal to one if we stage after burn $i$ and zero otherwise. It can stage at most $m$ times, where $m$ is the total number of burns required for that route. It assumes that the vehicle stages after the last burn $\left(S_{m}=1\right)$. Equation (45) defines the variable $f_{i}$ to represent the type of fuel used during stage $i$. The variable $f_{i}$ can take on integer values up to the number of different types of fuel available (the model do not allow hybrid stages, to ensure that the same type of fuel is used for consecutive burns in a single stage). First in (46) the total number of stages is computed $\left(N_{\text {stage }}\right)$. Next using the staging locations, the amount of $\Delta V$ required for each stage $\left(\Delta V_{i}\right)$ can be defined. The amount of $\Delta V$ in a given stage is the sum of the $\Delta V$ for each burn up to and including the first burn for which the vehicle stages $\left(S_{i}=1\right)$. Finally, the initial mass $\left(m_{0}\right)$ of the vehicle is calculated using the rocket equation. Equation (47) computes the vehicle wet mass (the mass of the structure and fuel without the payload mass).

3.6. Pipeline and Cable Transportation Problems. In the specialized literature there exist various variants of the pipeline and cable Transportation Problems. The main variants of the Pipeline and Cable Transportation Problems are water distribution network (WDN) [58, 59], bulk energy transportation networks [60], generalized network flow model or multiperiod generalized minimum cost flow problem [61, 62], water flow and chemical transport [63], $\mathrm{CO}_{2}$ pipeline transport $[64,65]$.

The coal, gas, water, and electricity production and transportation systems model [66] uses the fact that each of these subsystems depends on the integrated operation of a network together with a market, and it captures the strong coupling within and between the different energy subsystems. The mathematical framework using a network flow optimization model with data characterizing the actual national electric energy system as it exists today in the United States [66] is formed by (48)-(52):

$$
\begin{aligned}
& \min z= \sum_{\forall t} \sum_{\forall p} c_{p} \cdot E_{p p t}+\sum_{\forall t} \sum_{\forall g} g_{g} \cdot E_{g g t}+\sum_{\forall t} \sum_{\forall s} S_{s} \cdot E_{s s t} \\
&+\sum_{\forall t} \sum_{\forall p} \sum_{\forall g} \sum_{\forall m} t_{p g m t} \cdot E_{p g m t} \\
&+\sum_{\forall t} \sum_{\forall p} \sum_{\forall s} \sum_{\forall m} t_{p s m t} \cdot E_{p s m t} \\
&+\sum_{\forall t} \sum_{\forall s} \sum_{\forall g} \sum_{\forall m} t_{s g m t} \cdot E_{s g m t}+\sum_{\forall t} \sum_{\forall r} t_{r t} \cdot E_{r t}, \\
& E_{p p t}- \sum_{\forall g} \sum_{\forall m} E_{p g m t}-\sum_{\forall s} \sum_{\forall m} E_{p s m t}=0, \quad \forall p, \quad \forall t, \\
&-E_{s s t}+E_{s s, t-1}+\sum_{\forall p} \sum_{\forall m} E_{p s m t}-\sum_{\forall g} \sum_{\forall m} E_{s g m t}=0, \quad \forall s, \quad \forall t, \\
& \sum_{\forall s} \sum_{\forall m} E_{s g m t}+\sum_{\forall p} \sum_{\forall m} E_{p g m t}-E_{g g t}=0, \quad \forall g, \quad \forall \mathrm{t}, \\
& \sum_{\forall i} \eta_{i j} \cdot E_{i j}-\sum_{\forall k} E_{j k}=E_{j, \text { output }}-E_{j, \text { input }} \cdot
\end{aligned}
$$

The objective function (48) is equal to the total production cost + total generation cost + total storage cost + total transportation cost for the gas and coal subsystems, subject to energy balance at the production nodes (49), energy balance at the storage nodes (50), energy balance at the generation nodes (51), and energy balance at the electric transmission nodes (52), where $Z$ is the total cost (production, storage and transportation) of the energy over 1 year at weekly intervals; $p$ is the production node; $g$ is the generation node; $d$ is the electric transmission mode; $s$ is the storage node; $m$ is the transportation mode; $r$ is the transmission line, $c_{p}, g_{g}$, and $s_{s}$ are the per unit cost of extraction, generation (without including the fuel cost to avoid duplication), and storage; $t_{\text {pgmt }}, t_{\text {psmt }}$, and $t_{\text {sgmt }}$ are the per unit cost of gas or coal transportation from a production or storage node to a storage or generation node, using the transportation mode $m$ at time $t ; t_{r t}$ is the per unit cost of the electric energy transported by the transmission line $r$ at time $t ; E_{p p t}$ is the total energy produced in the production node $p$ during time $t ; E_{\text {sst }}$ is the energy at the storage facility $s$ at the end of time $t ; E_{g g t}$ is the total energy arriving to the generation facility $g$ at time $t$; $E_{\text {pgmt }}, E_{\text {psmt }}$, and $E_{\text {sgmt }}$ are the amount of energy going from a production or storage node to a storage or generation node, shipped using the transportation mode $m$ during the time $t$; $E_{r t}$ is the amount of electric energy flow in the transmission line $r$ during the time $t ; E_{d t}$ is the forecasted energy demand in the electric node $d$ during the time $t ; E_{s s, 0}$ and $E_{s s, T}$ are the energy in the storage facility $s$ at the beginning and end of the scheduling horizon; $\eta_{r}$ is the efficiency of the energy transmission line $r ; E_{i j}$ is the energy from node $i$ to node $j$; $E_{j k}$ is the energy from node $j$ to node $k ; E_{j \text {,input }}$ is the energy 
TABLE 1: Related Works.

\begin{tabular}{|c|c|c|}
\hline Algorithm & Problem & Contribution \\
\hline Multiphase heuristic [72] & $\begin{array}{l}\text { Multiperiod petrol station } \\
\text { replenishment problem }\end{array}$ & $\begin{array}{l}\text { A heuristic with a route construction and truck loading procedures, a route } \\
\text { packing procedure, and two procedures enabling the anticipation or the } \\
\text { postponement of deliveries for the MPSRP. }\end{array}$ \\
\hline Exact algorithm [45] & $\begin{array}{l}\text { Petrol station } \\
\text { replenishment problem }\end{array}$ & $\begin{array}{l}\text { The algorithm decomposes the problem into truck loading problem and a } \\
\text { routing problem. }\end{array}$ \\
\hline Genetic algorithm [73] & $\begin{array}{l}\text { Air transportation } \\
\text { scheduling problem }\end{array}$ & $\begin{array}{l}\text { The Taguchi experimental design method is applied to set and estimate the } \\
\text { proper values of gas parameters. }\end{array}$ \\
\hline $\begin{array}{l}\text { Simulated annealing } \\
\text { based heuristic algorithms } \\
{[74]}\end{array}$ & Air transportation & $\begin{array}{l}\text { The problem is formulated as a parallel machine scheduling problem with } \\
\text { earliness penalties. }\end{array}$ \\
\hline $\begin{array}{l}\text { Simulated annealing } \\
\text { algorithm [75] }\end{array}$ & $\begin{array}{l}\text { Arrival flight delays } \\
\text { problem }\end{array}$ & $\begin{array}{l}\text { Based on the characteristic of the flights and the thinking of system optimization, } \\
\text { this paper builds up dynamic optimizing models of the flight delays scheduling } \\
\text { with the objective function of delay cost. }\end{array}$ \\
\hline Greedy algorithm [76] & $\begin{array}{l}\text { Single-airport } \\
\text { ground-holding problem } \\
\text { (SAGHP) }\end{array}$ & $\begin{array}{l}\text { A dynamic programming formulation with a corresponding backward solution } \\
\text { algorithm. }\end{array}$ \\
\hline $\begin{array}{l}\text { Coevolutionay genetic } \\
\text { algorithm }[14,15]\end{array}$ & $\begin{array}{l}\text { Multiairport } \\
\text { ground-holding problem }\end{array}$ & Survey model with dynamic capacity in details. \\
\hline $\begin{array}{l}\text { Column generation based } \\
\text { heuristic algorithm [77] }\end{array}$ & Helicopter routing problem & $\begin{array}{l}\text { A MIP based heuristic with an add column generation procedures that improve } \\
\text { the solution quality for the Brazilian State Oil Company (Petrobras). }\end{array}$ \\
\hline Heuristic algorithm [42] & $\begin{array}{l}\text { Cash transportation vehicle } \\
\text { routing problem }\end{array}$ & $\begin{array}{l}\text { A solution algorithm based on a problem decomposition/collapsing technique, } \\
\text { coupled with the use of a mathematical programming software. }\end{array}$ \\
\hline Tabu search [78] & Helicopter routing problem & $\begin{array}{l}\text { Three routing policies are considered: a direct routing policy, a Hamiltonian } \\
\text { routing policy, and a general routing policy. }\end{array}$ \\
\hline $\begin{array}{l}\text { Hub-and-spoke } \\
\text { configuration [79] }\end{array}$ & Helicopter routing problem & $\begin{array}{l}\text { Mathematical model and theoretical results for route planning with a } \\
\text { safety-based objective for helicopter routing in the Norwegian oil industry. }\end{array}$ \\
\hline Genetic algorithm [80] & $\begin{array}{l}\text { Multiobjective helicopter } \\
\text { routing problem }\end{array}$ & A variation of the cluster-first route-second method for routing helicopters \\
\hline Transgenic algorithm [81] & $\begin{array}{l}\text { Vehicle routing problem } \\
\text { with time windows }\end{array}$ & $\begin{array}{l}\text { Horizontal gene transfer based on the transformation mechanism and an } \\
\text { intelligent mutation operator called Symbion operator. }\end{array}$ \\
\hline $\begin{array}{l}\text { Vertical transfer } \\
\text { algorithm [82] }\end{array}$ & School bus routing problem & A computer algorithm based on the mechanism of vertical gene transfer. \\
\hline $\begin{array}{l}\text { Particle swarm } \\
\text { optimisation [83] }\end{array}$ & $\begin{array}{l}\text { Vehicle routing problem } \\
\text { with time windows }\end{array}$ & $\begin{array}{l}\text { An improved hybrid particle swarm optimisation (IHPSO) method with some } \\
\text { postoptimisation procedures. }\end{array}$ \\
\hline Genetic algorithm [84] & $\begin{array}{l}\text { Vehicle routing problem } \\
\text { with time windows }\end{array}$ & Population preselection operators. \\
\hline Genetic algorithm [85] & $\begin{array}{l}\text { Vehicle routing problem } \\
\text { with time windows }\end{array}$ & $\begin{array}{l}\text { A physical parallelisation of a distributed real-coded genetic algorithm and a set } \\
\text { of eight subpopulations residing in a cube topology. }\end{array}$ \\
\hline Tabu search $[86]$ & $\begin{array}{l}\text { Vehicle routing problem } \\
\text { with time windows and } \\
\text { multidepot (VRPTW) }\end{array}$ & A unified Tabu search heuristic. \\
\hline Simulated annealing [87] & $\begin{array}{l}\text { Vehicle routing problem } \\
\text { with time windows }\end{array}$ & $\begin{array}{l}\text { A two-phase system (global neighbourhoods and local neighbourhood) of a } \\
\text { parallel simulated annealing. }\end{array}$ \\
\hline Simulated Annealing [88] & $\begin{array}{l}\text { Vehicle routing problem } \\
\text { with time windows }\end{array}$ & 2 interchanges with the best-accept-strategy. \\
\hline $\begin{array}{l}\text { Evolutionary Algorithm } \\
\text { [89] }\end{array}$ & $\begin{array}{l}\text { Vehicle routing problem } \\
\text { with time windows }\end{array}$ & $\begin{array}{l}\text { An individual representative called the strategy parameter used in the } \\
\text { recombination and mutation operators. }\end{array}$ \\
\hline Tabu Search $[90]$ & $\begin{array}{l}\text { Vehicle routing problem } \\
\text { with time windows }\end{array}$ & $\begin{array}{l}\text { The Tabu search with a neighbourhood of the current solution created through } \\
\text { an exchange procedure that swaps sequences of consecutive customers. }\end{array}$ \\
\hline Genetic Algorithm [91] & $\begin{array}{l}\text { Vehicle routing problem } \\
\text { with time windows }\end{array}$ & $\begin{array}{l}\text { A genetic routing system or GENEROUS based on the natural evolution } \\
\text { paradigm. }\end{array}$ \\
\hline GRASP [92] & $\begin{array}{l}\text { Vehicle routing problem } \\
\text { with time windows }\end{array}$ & A two-phase greedy randomised adaptive search to solve VRPTW. \\
\hline $\begin{array}{l}\text { Branch-and-Bound } \\
\text { method [93] }\end{array}$ & $\begin{array}{l}\text { Vehicle routing problem } \\
\text { with time windows }\end{array}$ & A Branch-and-Bound method to solve VRPTW. \\
\hline
\end{tabular}


TABLE 1: Continued.

\begin{tabular}{ll}
\hline Algorithm & Problem \\
\hline $\begin{array}{l}\text { A rural routing heuristic } \\
{[94]}\end{array}$ & School bus routing problem \\
\hline
\end{tabular}

Contribution

Constructing the initial route and then improving it by using a fixed tenure Tabu search algorithm.

The solution method starts with a GRASP-like saving algorithm, after which a

GRASP [95] School bus routing problem variable neighbourhood search algorithm is used to improve the initial solution

A modified version of the well-known transportation problem helps the metaheuristic to quickly assign students to stops.

Use the GENROUTER system to route school buses for two school districts. The

Genetic algorithm [96] School bus routing problem routes obtained by GENROUTER system were superior to those obtained by the

CHOOSE school bus routing system and the current routes in use by the two school districts.

To explore the solution space, where the revised simplex method evaluates,

Simulated annealing [97] Train formation problem selects, and implements the moves. The neighbourhood structure is based on the pivoting rules of the simplex method that provides an efficient method to reach the neighbours of the current solution.

Genetic algorithm [98] Train formation problem

Neural networks [99] Train formation problem

Generalized location

routing problem with space exploration or generalized location routing problem with profits (GLRPPs)

Column generation based heuristic [54]

Memetic algorithm [100] Helicopter routing problem

Genetic algorithm [101] Locomotive routing problem

\begin{tabular}{ll}
\hline Genetic algorithm [102] & $\begin{array}{l}\text { Locomotive routing } \\
\text { problem }\end{array}$ \\
\hline $\begin{array}{l}\text { Branch-and-bound } \\
\text { method [103] }\end{array}$ & $\begin{array}{l}\text { Locomotive routing } \\
\text { problem }\end{array}$ \\
\hline Heuristic algorithm [50] & Tour planning problem \\
\hline
\end{tabular}

Heuristic algorithm [104] Team orienteering problem

\begin{tabular}{|c|c|c|}
\hline Memetic algorithm [105] & Team orienteering problem & The memetic algorithm is a hybrid genetic algorithm using new algorithms. \\
\hline $\begin{array}{l}\text { Branch-and-price } \\
\text { algorithm [106] }\end{array}$ & Team orienteering problem & $\begin{array}{l}\text { Includes branching rules specifically devoted to orienteering problems and } \\
\text { adapts acceleration techniques in this context. }\end{array}$ \\
\hline $\begin{array}{l}\text { Tabu search algorithm } \\
\text { [107] }\end{array}$ & Team orienteering problem & $\begin{array}{l}\text { A variable neighbourhood search algorithm turned out to be more efficient and } \\
\text { effective for this problem than two Tabu search algorithms. }\end{array}$ \\
\hline $\begin{array}{l}\text { Ant colony optimization } \\
{[108]}\end{array}$ & Team c & $\begin{array}{l}\text { The sequential, deterministic-concurrent and random-concurrent,and } \\
\text { simultaneous methods are proposed to construct candidate solutions in the } \\
\text { framework of ACO. }\end{array}$ \\
\hline $\begin{array}{l}\text { Iterated local search } \\
\text { heuristic [109] }\end{array}$ & Team orienteering problem & $\begin{array}{l}\text { An algorithm that solves the team orienteering problem with time windows } \\
\text { (TOPTW). }\end{array}$ \\
\hline Simulated annealing [110] & Team orienteering problem & $\begin{array}{l}\text { Two versions of the proposed SA heuristic are developed and compared with } \\
\text { existing approaches. }\end{array}$ \\
\hline
\end{tabular}

The calibration and validation of the GA model are carried out for three different complexity levels of objective functions.

A training process for neural network development is conducted, followed by a testing process that indicates that the neural network model will probably be both sufficiently fast and accurate, in producing train formation plans.

The problem arises in exploration of planetary bodies where strategies correspond to different technologies. A description of the generalized location routing problem with profits and its mathematical formulation as an integer program are provided. Two solution methodologies to solve the problem-branch-and-price and a three-phase heuristic method combined with a generalized randomized adaptive search procedure-are proposed.

The personnel transportation within a set of oil platforms by one helicopter that may have to undertake several routes in sequence.

A cluster-first, the route-second approach is used to inform the multidepot locomotive assignment of a set of single depot problems and after that we solve each problem independently. Each single depot problem is solved heuristically by a hybrid genetic algorithm that in which push forward insertion heuristic (PFIH) is used to determine the initial solution and $\lambda$-interchange mechanism is used for neighbourhood search and improving the method.

The proposed solution approach is tested with real-world data from the Korean railway.

Backtracking mechanism that can be added to this heuristic branch-and-price approach.

A heuristic method based on local search ideas.

Bilevel filter-and-fan method for solving the capacitated team orienteering problem. Given a set of potential customers, each associated with a known profit and a predefined demand, and the objective of the problem is to select the subset of customers as well as to determine the visiting sequence and assignment to vehicle routes such that the total collected profit is maximized and route duration and capacity restrictions are satisfied.

The memetic algorithm is a hybrid genetic algorithm using new algorithms. adapts acceleration techniques in this context.

effective for this problem than two Tabu search algorithms.

The sequential, deterministic-concurrent and random-concurrent,an framework of ACO.

An algorithm that solves the team orienteering problem with time windows Two versions of the proposed SA heuristic are developed and compared with existing approaches. 
TABle 1: Continued.

\begin{tabular}{|c|c|c|}
\hline Algorithm & Problem & Contribution \\
\hline GRASP [111] & Team orienteering problem & $\begin{array}{l}\text { A greedy randomised adaptive search Procedure for solving the Team } \\
\text { orienteering problem. }\end{array}$ \\
\hline GLS, VNS, ILS [112] & $\begin{array}{l}\text { Tourist trip design } \\
\text { problems }\end{array}$ & $\begin{array}{l}\text { Guided local search (GLS) and variable neighbourhood search (VNS) are applied } \\
\text { to efficiently solve the TOP. Iterated local search (ILS) is implemented to solve } \\
\text { the TOPTW. }\end{array}$ \\
\hline Tabu search [113] & Team orienteering problem & $\begin{array}{l}\text { The Tabu search heuristic is embedded in an adaptive memory procedure that } \\
\text { alternates between small and large neighbourhood stages during the solution } \\
\text { improvement phase. Both random and greedy procedures for neighbourhood } \\
\text { solution generation are employed and infeasible, as well as feasible, solutions are } \\
\text { explored in the process. }\end{array}$ \\
\hline Tabu search [114] & $\begin{array}{l}\text { Truck and trailer routing } \\
\text { problem }\end{array}$ & $\begin{array}{l}\text { A solution construction method and a Tabu search improvement heuristic } \\
\text { coupled with the deviation concept found in deterministic annealing is } \\
\text { developed. }\end{array}$ \\
\hline $\begin{array}{l}\text { Simulated annealing } \\
{[115,116]}\end{array}$ & $\begin{array}{l}\text { Truck and trailer routing } \\
\text { problem }\end{array}$ & $\begin{array}{l}\text { The combination of a two-level solution representation with the use of dummy } \\
\text { depots/roots, and the random neighbourhood structure which utilizes three } \\
\text { different types of moves. }\end{array}$ \\
\hline GRASP [117] & $\begin{array}{l}\text { Truck } \\
\text { proble }\end{array}$ & A hybrid meta-heuristic based on GRASP, VNS and path relinking. \\
\hline Branch-and-cut [118] & $\begin{array}{l}\text { Maritime inventory routing } \\
\text { problem }\end{array}$ & $\begin{array}{l}\text { A case study of a practical maritime inventory routing problem (MIRP) shows } \\
\text { that the proposed neighbour and algorithmic framework are flexible and } \\
\text { effective enough to be a choice of model and solution method for practical } \\
\text { inventory routing problems. }\end{array}$ \\
\hline Branch-and-cut [119] & Inventory routing problem & $\begin{array}{l}\text { The algorithms could solve the instances with } 45 \text { and } 50 \text { customers, } 3 \text { periods } \\
\text { and } 3 \text { vehicles. }\end{array}$ \\
\hline Branch-and-cut [120] & Inventory routing problem & $\begin{array}{l}\text { The algorithm solves the IRP with several vehicles and with many products, each } \\
\text { with a specific demand, but sharing inventory and vehicle capacities. }\end{array}$ \\
\hline Branch-and-cut [121] & Invent & They implement a branch-and-cut algorithm to solve the model optimally. \\
\hline Branch-and-price $[122]$ & Inventory routing problem & $\begin{array}{l}\text { A new branching strategy to accommodate the unique degeneracy characteristics } \\
\text { of the master problem, and a new procedure for handling symmetry. A novel } \\
\text { column generation heuristic and a rounding heuristic were also implemented to } \\
\text { improve algorithmic efficiency. }\end{array}$ \\
\hline Local search [123] & Inventory routing problem & $\begin{array}{l}\text { Our model takes into account pickups, time windows, drivers' safety regulations, } \\
\text { orders, and many other real-life constraints. This generalization of the } \\
\text { vehicle-routing problem was often handled in two stages in the past: inventory } \\
\text { first, routing second. }\end{array}$ \\
\hline Genetic algorithm [124] & $\begin{array}{l}\text { Inventory-distribution } \\
\text { problem }\end{array}$ & $\begin{array}{l}\text { The delivery schedule represented in the form of a 2-dimensional matrix and two } \\
\text { random neighbourhood search mechanisms are designed. }\end{array}$ \\
\hline Genetic algorithm [125] & $\begin{array}{l}\text { Bus Terminal Location } \\
\text { Problem }\end{array}$ & A new crossover and mutation for the BTLP. \\
\hline $\begin{array}{l}\text { Branch-and-price method } \\
{[126]}\end{array}$ & $\begin{array}{l}\text { Maritime inventory routing } \\
\text { problem }\end{array}$ & $\begin{array}{l}\text { The method is tested on instances inspired from real-world problems faced by a } \\
\text { major energy company. }\end{array}$ \\
\hline $\begin{array}{l}\text { Variable neighbourhood } \\
\text { search [127] }\end{array}$ & Inventory routing problem & $\begin{array}{l}\text { A variable neighbourhood search (VNS) heuristic for solving a multiproduct } \\
\text { multiperiod IRP in fuel delivery with multi-compartment homogeneous } \\
\text { vehicles, and deterministic consumption that varies with each petrol station and } \\
\text { each fuel type. }\end{array}$ \\
\hline Branch-and-cut [128] & $\begin{array}{l}\text { Airline crew scheduling } \\
\text { problems }\end{array}$ & $\begin{array}{l}\text { The branch-and-cut solver generates cutting planes based on the underlying } \\
\text { structure of the polytope defined by the convex hull of the feasible integer points } \\
\text { and incorporates these cuts into a tree-search algorithm that uses automatic } \\
\text { reformulation procedures, heuristics and linear programming technology to } \\
\text { assist in the solution. }\end{array}$ \\
\hline Simulated annealing [129] & $\begin{array}{l}\text { Airline crew scheduling } \\
\text { problems }\end{array}$ & $\begin{array}{l}\text { Computational results are reported for some real-world short-to medium-haul } \\
\text { test problems with up to } 4600 \text { flights per month. }\end{array}$ \\
\hline Simulated annealing [130] & $\begin{array}{l}\text { Airline crew scheduling } \\
\text { problems }\end{array}$ & $\begin{array}{l}\text { The first step uses the "pilot-by-pilot" heuristic algorithm to generate an initial } \\
\text { feasible solution. The second step uses the Simulated Annealing technique for } \\
\text { multi-objective optimization problems to improve the solution obtained in the } \\
\text { first step. }\end{array}$ \\
\hline
\end{tabular}


TABle 1: Continued.

\begin{tabular}{ll}
\hline Algorithm & Problem \\
\hline Genetic algorithms [131] & $\begin{array}{l}\text { Airline crew scheduling } \\
\text { problems }\end{array}$
\end{tabular}

Simulated annealing [132] Train scheduling problem

Genetic algorithm [133] Train scheduling problem

Genetic algorithm [134] Train scheduling problem

Genetic algorithm [135] Train dispatching problem

\begin{tabular}{ll} 
Genetic algorithm [136] & Train timetable problem \\
\hline ACO [137] & Railroad blocking problem
\end{tabular}

Very large-scale

Very large-scale
neighbourhood [71]

Contribution

The development and application of a hybrid genetic algorithm to airline crew scheduling problems. The hybrid algorithm consists of a steady-state genetic algorithm and a local search heuristic. The hybrid algorithm was tested on a set of 40 real-world problems.

They integrated the train routing the train routing problem and the train scheduling problem. They used simulated annealing to solve the problem. The objective is to minimize operational costs (fuel, crew, capital, and freight car rental costs) without missing cars.

They applied GA for solving the freight train scheduling problem in a single track railway system.

They solved the passenger train scheduling problem by attempting to minimize the waiting time for passengers changing trains. They proposed a GA with a greedy algorithm to obtain the sub-optimal solutions.

A model for train dispatching on lines with double tracks. The model can optimize train dispatching by adjusting the order and times of train departures from stations, and then the efficiency of the method is demonstrated by simulation of the Guangzhou to Shenzhen high-speed railway.

To obtain the optimal train timetables to minimize delay and changes of gates, they divided the railway network into multiple block, used the branch-and-bound method to determine the train sequence for each block, and calculate the train times. They applied GA to improve the solutions.

An ant colony optimization algorithm for solving RBP. The solution method is applied to build a car blocking plan in the Islamic Republic of Iran Railways.

An algorithm using a technique known as very large-scale neighbourhood (VLSN) search that is able to solve the problem to near optimality using one to two hours of computer time on a standard workstation computer.

A new formulation for RBP in coal heavy haul rail network in north China. An improved ACO to solve a new formulation for RBP in coal heavy haul rail

ACO [138] Railroad blocking problem network in north China. They discussed the problem with direct train routing and frequencies and they did not consider the terminal capacity in handling classification process and maximum available blocks constraints.

A taxonomy and a comprehensive review of applications of MOEAs in

Multiobjective evolutionary algorithms [139]

Aeronautical and aerospace design problems aeronautical and aerospace design problems. They provide a set of general guidelines for using and designing MOEAs for aeronautical and aerospace engineering problems.

Genetic algorithms [140] Aerospace problems The paper uses GA to solve $\mathrm{H}-2$ and $\mathrm{H}$-infinity norm model reduction problems and helps obtain globally optimized nominal models. \begin{tabular}{ll}
\hline Genetic algorithms [44] & $\begin{array}{l}\text { Military transport planning } \\
(\text { MTP })\end{array}$
\end{tabular}

They study a logistics problem arising in military transport planning. A Niche genetic algorithm, together with a hybridized variant, is applied to the problem. A matheuristic that uses a GRASP construction phase followed by a variable GRASP [141] School bus routing problem neighbourhood descent (VND) improvement phase to solve 112 instances with 5 stops and 25 students to 80 stops and 800 students of the SBRP.

A hybrid evolutionary computation based on an artificial ant colony with a ACO [142] School bus routing problem variable neighbourhood local search algorithm to solve the urban bus routing problem in the Tunisian case.

Hybrid algorithm [143] School bus routing problem

A mixed load improvement algorithm to solve 48 test instances for the SBRP with a number of schools 6, 12, 25, 50, and 100 and bus stops 250, 500, 1000, and 2000.

In addition to the min-max vehicle routing problem criterion imposed on the time it takes to complete the longest route, school districts are concerned with the minimization of the total distance travelled and they develop a solution

Tabu search [144] procedure for this problem by applying Tabu search within the framework of Multiobjective Adaptive Memory Programming and compare it to an implementation of the Non-dominated Sorting Genetic Algorithm - a well-known approach to multiobjective optimization. 
TABle 1: Continued.

\begin{tabular}{lll}
\hline Algorithm & Problem & Contribution \\
\hline Hybrid algorithm [145] & $\begin{array}{l}\text { For a school bus routing problem, called the MV-TPP-RC, which combines a bus } \\
\text { stop selection and bus route generation with additional constraints on certain } \\
\text { Problem }\end{array}$ & $\begin{array}{l}\text { resources, we have developed a BCP algorithm as an implementation of a set } \\
\text { partitioning formulation proposed for that problem. This formulation has been } \\
\text { obtained from a Dantzig-Wolfe decomposition of a three-index variables model } \\
\text { that describes the MV-TPP-RC. }\end{array}$ \\
\hline
\end{tabular}

from outside the system to node $j$; and $E_{j \text {,output }}$ is the energy from node $j$ to outside the system (electric demand).

3.7. Intermodal Transportation Problems. The Intermodal Transportation Problems using more than one transportation mode are as follows. The main variants of the Intermodal Transportation Problems are intermodal multicommodity routing problem with scheduled services [67], tour planning problem (TPP) [50], tourist trip design problems [68], railroad blocking problem (RBP) [69], and intertemporal demand for international tourist air travel [70].

The railroad blocking problem (RBP) is a multicommodity-flow, network-design, and routing problem [71], and RBP is the railroad blocking problem which is one of the most important decisions in freight railroads. The mathematical model of RBP [69] is formed by (53)-(59):

$$
\begin{aligned}
& \operatorname{Min} z=\sum_{k \in K} \sum_{a \in A} c_{a} v_{k} x_{a}^{k}, \\
& \sum_{\substack{a \in A \\
\operatorname{orig}(a)=i}} x_{a}^{k}-\sum_{\substack{a \in A \\
\operatorname{dest}(a)=i}} x_{a}^{k} \\
& = \begin{cases}1, & \operatorname{orig}(a)=i, \\
-1, & \operatorname{dest}(a)=i, \quad \forall i \in N, k \in K, \\
0, & \text { otherwise, }\end{cases} \\
& \sum_{k \in K} v_{k} x_{a}^{k} \leq u_{a} y_{a}, \quad \forall a \in A, \\
& \sum_{\substack{a \in A \\
\operatorname{orig}(a)=i}} y_{a} \leq B(i), \quad \forall i \in N, \\
& \sum_{k \in K} \sum_{\substack{a \in A \\
\operatorname{orig}(a)=i}} v_{k} x_{a}^{k} \leq V(i), \quad \forall i \in N, \\
& y_{a} \in\{0,1\}, \quad \forall a \in A, \\
& x_{a}^{k} \in\{0,1\}, \quad \forall a \in A, \forall k \in K,
\end{aligned}
$$

where $G=(N, A)$ is the graph with terminal set $N$ and potential blocks set $A, K$ is the set of all commodities $k$ designated by an origin-destination pair of nodes, $v_{k}$ is the volume of commodity $k$, orig $(k)$ is the origin terminal for commodity $k$, $\operatorname{dest}(k)$ is the destination terminal for commodity $k$, orig $(a)$ is the origin of potential block $a, \operatorname{dest}(a)$ is the destination of potential block $a, u_{a}$ is the capacity of potential block $a$, $c_{a}$ is the per unit cost of flow on arc $a$ (assumed equal for all commodities), $B(i)$ is the number of blocks which may originate at terminal $I$, and $V(i)$ is the volume which may be classified at terminal $i, x_{k}=1$, if commodity $k$ is flowing on block $a, 0$ otherwise. $Y_{a}=1$ if block $a$ is included in the blocking network, 0 otherwise.

The objective of the railroad blocking problem $(\mathrm{RBP})$ is to minimize the sum of the costs of delivering each commodity using the blocking network formed by blocks for which $y_{a}=$ 1 (53). In (54), for each terminal there are balance equations for the flow of each commodity. For each potential block, equations in (55) prevent flow on blocks which are not built and enforce the upper bound $u_{a}$ on flow for blocks which are built. The constraints (56) enforce the terminal limit $B(i)$ for the sum of the blocks which leave the terminal. The constraints (57), (58), and (59) model the volume of cars, which may be classified at each terminal.

\section{Algorithms to Solve Transportation Problems}

Various algorithms to solve the Transportation Problems (Table 1) may be found in the literature. We mention only some of the most popular algorithms to solve the Transportation Problems.

\section{Conclusions}

The paper survey mathematical models and algorithms used to solve different types of transportation modes by air, water, space, cables, tubes, and road. It presents the variants, classification, and the general parameters of the Transportation Problems.

As future work, we propose to investigate mathematical models of the space transportation problems, maritime transportation issues, and the creation of new algorithms that solve these problems.

\section{Conflict of Interests}

The authors declare that there is no conflict of interests regarding the publication of this paper.

\section{Acknowledgment}

This work was supported by SEP-PROMEP (Mexico) through Grant PROMEP/103.5/12/8060 and by UNACAR-DES-DACI through grant POA 2014. 


\section{References}

[1] B. O. Øvstebø, L. M. Hvattum, and K. Fagerholt, "Optimization of stowage plans for RoRo ships," Computers and Operations Research, vol. 38, no. 10, pp. 1425-1434, 2011.

[2] L. C. Kendall and J. J. Buckley, The Business of Shipping, Cornell Maritime Press, 7th edition, 2001.

[3] K. Fagerholt, "Optimal fleet design in a ship routing problem," International Transactions in Operational Research, vol. 6, no. 5, pp. 453-464, 1999.

[4] F. Al-Khayyal and S. J. Hwang, "Inventory constrained maritime routing and scheduling for multi-commodity liquid bulk. I: applications and model," European Journal of Operational Research, vol. 176, no. 1, pp. 106-130, 2007.

[5] J. Laderman, L. Gleiberman, and J. F. Egan, "Vessel allocation by linear programming," Naval Research Logistics Quarterly, vol. 13, no. 3, pp. 315-320, 1996.

[6] K. Fagerholt, "A computer-based decision support system for vessel fleet scheduling-experience and future research," Decision Support Systems, vol. 37, no. 1, pp. 35-47, 2004.

[7] M. Christiansen, K. Fagerholt, and B. Nygreen, "Maritime transportation," in Handbooks in Operations Research and Management Science, C. Barnhart and G. Laporte, Eds., vol. 14, chapter 4, pp. 189-284, 2007.

[8] G. B. Dantzig and D. R. Fulkerson, "Minimizing the number of tankers to meet a fixed schedule," Naval Research Logistics Quarterly, vol. 1, no. 3, pp. 217-222, 1954.

[9] H. D. Sherali, S. M. Al-Yakoob, and M. M. Hassan, "Fleet management models and algorithms for an oil-tanker routing and scheduling problem," IIE Transactions, vol. 31, no. 5, pp. 395-406, 1999.

[10] C. Douligeris, E. Iakovou, J. D. Englehardt, H. Li, C. M. Ip, and C. N. K. Mooers, "Development of a national marine oil transportation system model," Spill Science and Technology Bulletin, vol. 4, no. 2, pp. 113-121, 1997.

[11] I. Norstad, K. Fagerholt, and G. Laporte, "Tramp ship routing and scheduling with speed optimization," Transportation Research C, vol. 19, no. 5, pp. 853-865, 2011.

[12] J. A. Ruiz-Vanoye and O. Díaz-Parra, "Maritime platform transport problem of solid, special and dangerous waste".

[13] M. Hellme, "Reducing air traffic delay in a space-time network," in Proceedings of the IEEE International Conference on Systems, Man and Cybernetics, vol. 1, pp. 236-242, October 1992.

[14] G. Andreatta, L. Brunetta, and G. Guastalla, "Multi-airport ground holding problem: a heuristic approach based on priority rules," in Modeling and Simulation in Air Traffic Management, L. Bianco, P. Dell'Olmo, and A. R. Odoni, Eds., pp. 71-87, Springer, 1997.

[15] X. Zhang, Y. Zhou, B. Liu, and Z. Wang, "The air traffic flow management with dynamic capacity and Co-evolutionary genetic algorithm," in Proceedings of the 10th International IEEE Conference on Intelligent Transportation Systems (ITSC '07), pp. 580-585, October 2007.

[16] L. Bianco, G. Rinaldi, and A. Sassano, "A combinatorial optimization approach to aircraft sequencing problem," in Flow Control of Congested Networks, A. R. Odoni, L. Bianco, and G. Szego, Eds., pp. 323-339, Springer, 1987.

[17] M. Timlin and W. Pulleyblank, "Precedence constraints routing and helicopter scheduling: heuristic design," Interfaces, vol. 22, no. 3, pp. 100-111, 1992.
[18] J. P. Arabeyre, J. Feanley, F. C. Stieger, and W. Teather, "The airline crew scheduling problem: a survey," Transportation Science, vol. 3, no. 2, pp. 140-163, 1969.

[19] O. Díaz-Parra and J. A. Ruiz-Vanoye, "Oil platform transport problem".

[20] K. Li, V. K. Ganesan, and A. I. Sivakumar, "Scheduling of single stage assembly with air transportation in a consumer electronic supply chain," Computers and Industrial Engineering, vol. 51, no. 2, pp. 264-278, 2006.

[21] K. Li, V. K. Ganesan, A. I. Sivakumar, and M. Mathirajan, "Methodologies for synchronised scheduling of assembly and air transportation in a consumer electronics supply chain," International Journal of Logistics Systems and Management, vol. 2, no. 1, pp. 52-67, 2006.

[22] R. Ghanbari and N. Mahdavi-Amiri, "Solving bus terminal location problems using evolutionary algorithms," Applied Soft Computing Journal, vol. 11, no. 1, pp. 991-999, 2011.

[23] D. Goldstein, T. Shehab, J. Casse, and H. C. Lin, "On the formulation and solution of the convoy routing problem," Transportation Research E, vol. 46, no. 4, pp. 520-533, 2010.

[24] A. M. Cambell, L. Clarke, A. J. Kleywegt, and M. W. P. Savelsbergh, "The inventory routing problem," in Fleet Management and Logistics, T. G. Crainic and G. Laporte, Eds., pp. 95-113, Springer, Boston, Mass, USA, 1998.

[25] S. C. Liu and W. T. Lee, "A heuristic method for the inventory routing problem with time windows," Expert Systems with Applications, vol. 38, no. 10, pp. 13223-13231, 2011.

[26] R. M. Newton and W. H. Thomas, "Bus routing in a multi-school system," Computers and Operations Research, vol. 1, no. 2, pp. 213-222, 1974.

[27] C. Zhu, J. Q. Hu, F. Wang, Y. Xu, and R. Cao, "On the tour planning problem," Annals of Operations Research, vol. 192, pp. 67-86, 2012.

[28] I. M. Chao, "A tabu search method for the truck and trailer routing problem," Computers and Operations Research, vol. 29, no. 1, pp. 33-51, 2002.

[29] A. L. Kok, E. W. Hans, and J. M. J. Schutten, "Optimizing departure times in vehicle routes," European Journal of Operational Research, vol. 210, no. 3, pp. 579-587, 2011.

[30] M. C. Bolduc, G. Laporte, J. Renaud, and F. F. Boctor, "A tabu search heuristic for the split delivery vehicle routing problem with production and demand calendars," European Journal of Operational Research, vol. 202, no. 1, pp. 122-130, 2010.

[31] J. L. Saha, "An algorithm for bus scheduling problems," Operational Research Quarterly, vol. 21, pp. 463-474, 1970.

[32] M. L. Balinski and R. E. Quandt, "On an integer program for a delivery problem," Operations Research, vol. 12, no. 2, pp. 300 304, 1964.

[33] B. Gavish and P. Schweitzer, "An algorithm for combining truck trips," Transportation Science, vol. 8, no. 1, pp. 13-23, 1974.

[34] F. Li, B. Golden, and E. Wasil, "The open vehicle routing problem: algorithms, large-scale test problems, and computational results," Computers and Operations Research, vol. 34, no. 10, pp. 2918-2930, 2007.

[35] C. D. Foster, “The Transport Problem,” Monograph 00239144 , Transportation Research Board, 1963.

[36] Ü. Yüceer and A. Özakça, "A truck loading problem," Computers \& Industrial Engineering, vol. 58, no. 4, pp. 766-773, 2010.

[37] G. B. Dantzig and J. H. Ramser, "The truck dispatching problem," Management Science, vol. 6, no. 1, pp. 80-91, 1959. 
[38] F. Cornillier, F. F. Boctor, G. Laporte, and J. Renaud, "A heuristic for the multi-period petrol station replenishment problem," European Journal of Operational Research, vol. 191, no. 2, pp. 295-305, 2008.

[39] F. Cornillier, F. F. Boctor, G. Laporte, and J. Renaud, "An exact algorithm for the petrol station replenishment problem," Journal of the Operational Research Society, vol. 59, no. 5, pp. 607-615, 2008.

[40] P. Toth and D. Vigo, The Vehicle Routing Problem Discrete Math, SIAM Monographs on Discrete Mathematics and Applications, 2002.

[41] S. A. Brownlow and S. R. Watson, "Structuring multi-attribute value hierarchies," Journal of the Operational Research Society, vol. 38, no. 4, pp. 309-317, 1987.

[42] S. Yan, S. S. Wang, and M. W. Wu, "A model with a solution algorithm for the cash transportation vehicle routing and scheduling problem," Computers \& Industrial Engineering, vol. 63, no. 2, pp. 464-473, 2012.

[43] I. M. Chao, B. L. Golden, and E. A. Wasil, "The team orienteering problem," European Journal of Operational Research, vol. 88, no. 3, pp. 464-474, 1996.

[44] H. C. Lau, K. M. Ng, and X. Wu, "Transport logistics planning with service-level constraints," in Proceedings of the 19th National Conference on Artificial Intelligence (AAAI '04), pp. 519-524, July 2004.

[45] F. Cornillier, G. Laporte, F. F. Boctor, and J. Renaud, “The petrol station replenishment problem with time windows," Computers and Operations Research, vol. 36, no. 3, pp. 919-935, 2009.

[46] J. Park and B. I. Kim, "The school bus routing problem: a review," European Journal of Operational Research, vol. 202, no. 2, pp. 311-319, 2010.

[47] B. Gavish and E. Shlifer, "An approach for solving a class of transportation scheduling problems," European Journal of Operational Research, vol. 3, no. 2, pp. 122-134, 1979.

[48] J. F. Cordeau, P. Toth, and D. Vigo, "A survey of optimization models for train routing and scheduling," Transportation Science, vol. 32, no. 4, pp. 380-404, 1998.

[49] B. Vaidyanathan, R. K. Ahuja, and J. B. Orlin, "The locomotive routing problem," Transportation Science, vol. 42, no. 4, pp. 492$507,2008$.

[50] C. Zhu, J. Q. Hu, F. Wang, Y. Xu, and R. Cao, "On the tour planning problem," Annals of Operations Research, vol. 192, pp. 67-86, 2012.

[51] D. Huisman, L. G. Kroon, R. M. Lentink, and M. J. C. M. Vromans, "Operations research in passenger railway transportation," Statistica Neerlandica, vol. 59, no. 4, pp. 467-497, 2005.

[52] J. Sessions and G. Paredes, "A solution procedure for the sort yard location problem in forest operations," Forest Products Journal, vol. 33, no. 3, pp. 750-762, 1987.

[53] U. Brännlund, P. O. Lindberg, A. Nõu, and J. E. Nilsson, "Railway timetabling using Lagrangian relaxation," Transportation Science, vol. 32, no. 4, pp. 358-369, 1998.

[54] J. Ahn, O. de Weck, Y. Geng, and D. Klabjan, "Column generation based heuristics for a generalized location routing problem with profits arising in space exploration," European Journal of Operational Research, vol. 223, no. 1, pp. 47-59, 2012.

[55] C. Taylor and O. L. de Weck, "Concurrent trajectory and vehicle optimization: a case study of earth-moon supply chain logistics," in Proceedings of the 46th AIAA/ASME/ASCE/AHS/ASC Structures, Structural Dynamics and Materials Conference, pp. 50345046, Austin, Tex, USA, April 2005.
[56] M. Nakamiya, H. Yamakawa, D. J. Scheeres, and M. Yoshikawa, "Interplanetary transfers between Halo orbits: connectivity between escape and capture trajectories," Journal of Guidance, Control, and Dynamics, vol. 33, no. 3, pp. 803-813, 2010.

[57] S. Gong, J. Li, and H. Baoyin, "Solar sail transfer trajectory from L1 point to sub-L1 point," Aerospace Science and Technology, vol. 15 , no. 7, pp. 544-554, 2011.

[58] K. Lansey and L. Mays, "Optimization model for water distribution system design," Journal of Hydraulic Engineering, vol. 115, no. 10, pp. 1401-1418, 1989.

[59] U. Shamir, "Water distribution systems analysis," Journal of Hydraulic Engineering, vol. 94, no. 1, pp. 219-222, 1968.

[60] S. M. Ryan and J. D. Mccalley, "Decision models for bulk energy transportation networks," in Proceedings of the NSF IREE 2008 Grantees Conference, trip report, Washington, DC, USA, May 2008.

[61] A. Quelhas, E. Gil, J. D. McCalley, and S. M. Ryan, "A multiperiod generalized network flow model of the U.S. integrated energy system. Part I: model description," IEEE Transactions on Power Systems, vol. 22, no. 2, pp. 829-836, 2007.

[62] A. Quelhas and J. D. McCalley, "A multiperiod generalized network flow model of the U.S. integrated energy system. Part II: simulation results," IEEE Transactions on Power Systems, vol. 22, no. 2, pp. 837-844, 2007.

[63] T. C. Jim Yeh, R. Srivastava, A. Guzman, and T. Harter, "Numerical model for water flow and chemical transport in variably saturated porous media," Ground Water, vol. 31, no. 4, pp. 634-644, 1993.

[64] R. Doctor, A. Palmer, D. Coleman et al., "Transport of $\mathrm{CO}_{2}$," in IPCC Special Report on Carbon Dioxide Capture and Storage, B. Metz, O. Davidson, H. de Coninck, M. Loos, and L. Meyer, Eds., Cambridge University Press, Cambridge, UK, 2005.

[65] S. T. McCoy and E. S. Rubin, "An engineering-economic model of pipeline transport of $\mathrm{CO}_{2}$ with application to carbon capture and storage," International Journal of Greenhouse Gas Control, vol. 2, no. 2, pp. 219-229, 2008.

[66] E. M. Gil, A. M. Quelhas, J. D. McCalley, and T. van Voorhis, "Modeling integrated energy transportation networks for analysis of economic efficiency and network interdependencies," in Proceedings of 35 th North America Power Symposium (NAPS '03), Rolla, Mo, Usa, 2003.

[67] B. Ayar and H. Yaman, "An intermodal multicommodity routing problem with scheduled services," Computational Optimization and Applications, vol. 53, no. 1, pp. 131-153, 2012.

[68] P. Vansteenwegen and D. van Oudheusden, "The mobile tourist guide: an OR opportunity," OR Insights, vol. 20, no. 3, pp. 21-27, 2007.

[69] H. N. Newton, Network design under budget constraints with application to the railroad blocking problem [Ph.D. thesis], Auburn University, Auburn, Ala, USA, 1996.

[70] C. I. Hsua, H. C. Lib, and L. H. Yanga, "Intertemporal demand for international tourist air travel," Transportmetrica A, vol. 9, no. 5, pp. 385-407, 2013.

[71] R. K. Ahuja, K. C. Jha, and J. Liu, "Solving real-life railroad blocking problems," Interfaces, vol. 37, no. 5, pp. 404-419, 2007.

[72] F. Cornillier, F. F. Boctor, G. Laporte, and J. Renaud, "A heuristic for the multi-period petrol station replenishment problem," European Journal of Operational Research, vol. 191, no. 2, pp. 295-305, 2008.

[73] M. R. Delavar, M. Hajiaghaei-Keshteli, and S. Molla-AlizadehZavardehi, "Genetic algorithms for coordinated scheduling 
of production and air transportation," Expert Systems with Applications, vol. 37, no. 12, pp. 8255-8266, 2010.

[74] K. Li, A. I. Sivakumar, and V. K. Ganesan, "Complexities and algorithms for synchronized scheduling of parallel machine assembly and air transportation in consumer electronics supply chain," European Journal of Operational Research, vol. 187, no. 2, pp. 442-455, 2008.

[75] T. Jungai and X. Hongjun, "Optimizing arrival flight delay scheduling based on simulated annealing algorithm," Physics Procedia, vol. 33, pp. 348-353, 2012.

[76] P. Dell'Olmo and G. Lulli, "A dynamic programming approach for the airport capacity allocation problem," IMA Journal of Management Mathematics, vol. 14, no. 3, pp. 235-249, 2003.

[77] L. Moreno, M. Poggi de Aragão, and E. Uchoa, "Column generation based heuristic for a helicopter routing problem," in Experimental Algorithms, vol. 4007 of Lecture Notes in Computer Science, pp. 219-230, 2006.

[78] F. Qian, I. Gribkovskaia, G. Laporte, and Ø. Halskau Sr., "Passenger and pilot risk minimization in offshore helicopter transportation," Omega, vol. 40, no. 5, pp. 584-593, 2012.

[79] F. Qian, I. Gribkovskaia, and Ø. Halskau Sr., "Helicopter routing in the Norwegian oil industry: including safety concerns for passenger transport," International Journal of Physical Distribution and Logistics Management, vol. 41, no. 4, pp. 401-415, 2011.

[80] F. Qian, "Genetic algorithm for solving a multi-objective helicopter routing problem," in Proceedings of the 1st International Conference on Operations Research and Enterprise (ICORES '12), pp. 458-461, 2012.

[81] J. A. Ruiz-Vanoye, D. Ocotlán, F. Cocón, A. Buenabad-Arias, and A. Canepa Saenz, "A transgenic algorithm for the vehicle routing problem with time windows," in Proceedings of the 4rth World Congress on Nature and Biologically Inspired Computing (NaBIC '12), pp. 138-143, Mexico City, Mexico, November 2012.

[82] O. Díaz-Parra, J. A. Ruiz-Vanoye, A. Buenabad-Arias, and F. Cocón, "A vertical transfer algorithm for the school bus routing problem," in Proceedings of the 4rth World Congress on Nature and Biologically Inspired Computing (NaBIC '12), pp. 66-71, Mexico City, Mexico, November 2012.

[83] Z. Wang, J. Fan, J. Li, and C. Fan, "Research on improved hybrid particle swarm optimization for vehicle routing problem with time windows," in Proceedings of the 2010 International Conference on Artificial Intelligence and Computational Intelligence (AICI '10), vol. 1, pp. 179-183, Sanya, China, October 2010.

[84] O. Díaz-Parra, J. A. Ruiz-Vanoye, and J. C. Zavala-Díaz, "Population pre-selection operators used for generating a nonrandom initial population to solve vehicle routing problem with time windows," Scientific Research and Essays, vol. 5, no. 22, pp. 3529-3537, 2010.

[85] E. Alba, F. Luna, A. J. Nebro, and J. M. Troya, "Parallel heterogeneous genetic algorithms for continuous optimization," Parallel Computing, vol. 30, no. 5-6, pp. 699-719, 2004.

[86] J. F. Cordeau, G. Laporte, and A. Mercier, "A unified tabu search heuristic for vehicle routing problems with time windows," Journal of the Operational Research Society, vol. 52, no. 8, pp. 928-936, 2001.

[87] O. Arbelaitz and C. Rodriguez, "Low cost parallel solutions for the VRPTW optimization problem," International Journal of Computational Science and Engineering, vol. 1, no. 2-4, pp. 175$182,2001$.

[88] K. C. Tan, L. H. Lee, and K. Q. Zhu, "Heuristic methods for vehicle routing problem with time windows," in Proceedings of the 6th International Symposium on Artificial Intelligence \& Mathematics, Ft. Lauderdale, Fla, USA, 2000.

[89] J. Homberger and H. Gehring, "Two evolutionary metaheuristics for the vehicle routing problem with time windows," INFOR Journal, vol. 37, pp. 297-318, 1999.

[90] É. Taillard, P. Badeau, M. Gendreau, F. Guertin, and J. Y. Potvin, "A tabu search heuristic for the vehicle routing problem with soft time windows," Transportation Science, vol. 31, no. 2, pp. 170-186, 1997.

[91] J. Y. Potvin and S. Bengio, "The vehicle routing problem with time windows part II: genetic search," INFORMS Journal on Computing, vol. 8, no. 2, pp. 165-172, 1996.

[92] G. A. Kontoravdis and J. F. Bard, "A GRASP for the vehicle routing problem with time windows," Journal on Computing, vol. 7, no. 1, pp. 10-23, 1995.

[93] A. W. J. Kolen, A. H. G. Rinnooy Kan, and H. W. J. M. Trienekens, "Vehicle routing with time windows," Operations Research, vol. 35, no. 2, pp. 266-273, 1987.

[94] D. Ripplinger, "Rural school vehicle routing problem," Transportation Research Record, no. 1922, pp. 105-110, 2005.

[95] P. Schittekat, K. Sörensen, M. Sevaux, and J. Springael, "A metaheuristic for solving large instances of the school bus routing problem," in Proceedings of the 22nd European Conference on Operational Research (EURO '07), Prague, Czech Republic, July 2007.

[96] S. R. Thangiah and K. E. Nygard, "School bus routing using genetic algorithms," in Applications of Artificial Intelligence X: Knowledge-Based Systems, vol. 1707 of Proceedings of SPIE, pp. 387-398, The International Society for Optical Engineering, April 1992.

[97] M. Yaghini, M. Momeni, and M. Sarmadi, "Solving train formation problem using simulated annealing algorithm in a simplex framework," Journal of Advanced Transportation, 2012.

[98] D. Martinelli and H. Teng, "Genetic algorithm approach for solving the train formation problem," Transportation Research Record, no. 1497, pp. 62-69, 1995.

[99] D. R. Martinelli and H. Teng, "Optimization of railway operations using neural networks," Transportation Research C, vol. 4, no. 1, pp. 33-49, 1996.

[100] N. Velasco, P. Castagliola, P. Dejax, C. Guéret, and C. Prins, "A memetic algorithm for a pick-up and delivery problem by helicopter," Studies in Computational Intelligence, vol. 161, pp. 173-190, 2009.

[101] K. Ghoseiri and S. F. Ghannadpour, "A hybrid genetic algorithm for multi-depot homogenous locomotive assignment with time windows," Applied Soft Computing Journal, vol. 10, no. 1, pp. 5365, 2010.

[102] J. W. Chung, S. M. Oh, and I. C. Choi, "A hybrid genetic algorithm for train sequencing in the Korean railway," Omega, vol. 37, no. 3, pp. 555-565, 2009.

[103] S. Rouillon, G. Desaulniers, and F. Soumis, "An extended branch-and-bound method for locomotive assignment," Transportation Research B, vol. 40, no. 5, pp. 404-423, 2006.

[104] C. D. Tarantilis, F. Stavropoulou, and P. P. Repoussis, "The capacitated team orienteering problem: a bi-level filter-and-fan method," European Journal of Operational Research, vol. 224, no. 1, pp. 65-78, 2013.

[105] H. Bouly, D. C. Dang, and A. Moukrim, "A memetic algorithm for the team orienteering problem," $4 O R$, vol. 8, no. 1, pp. 49-70, 2010. 
[106] S. Boussier, D. Feillet, and M. Gendreau, "An exact algorithm for team orienteering problems," $4 O R$, vol. 5, no. 3, pp. 211-230, 2007.

[107] C. Archetti, A. Hertz, and M. G. Speranza, "Metaheuristics for the team orienteering problem," Journal of Heuristics, vol. 13, no. 1, pp. 49-76, 2007.

[108] L. Ke, C. Archetti, and Z. Feng, "Ants can solve the team orienteering problem," Computers and Industrial Engineering, vol. 54, no. 3, pp. 648-665, 2008.

[109] P. Vansteenwegen, W. Souffriau, G. Vanden Berghe, and D. van Oudheusden, "Iterated local search for the team orienteering problem with time windows," Computers and Operations Research, vol. 36, no. 12, pp. 3281-3290, 2009.

[110] S. W. Lin and V. F. Yu, "A simulated annealing heuristic for the team orienteering problem with time windows," European Journal of Operational Research, vol. 217, no. 1, pp. 94-107, 2012.

[111] W. Souffriau, P. Vansteenwegen, G. Vanden Berghe, and D. van Oudheusden, "A greedy randomized adaptive search procedure for the team orienteering problem," in Proceedings of the 9th EU/Meeting on Metaheuristics for Logistics and Vehicle Routing, Troyes, France, October 2008.

[112] P. Vansteenwegen, W. Souffriau, G. vanden Berghe, and D. van Oudheusden, "Metaheuristics for tourist trip planning," in Metaheuristics in the Service Industry, vol. 624 of Lecture Notes in Economics and Mathematical Systems, pp. 15-31, 2009.

[113] H. Tang and E. Miller-Hooks, "A TABU search heuristic for the team orienteering problem," Computers and Operations Research, vol. 32, no. 6, pp. 1379-1407, 2005.

[114] I. M. Chao, "A tabu search method for the truck and trailer routing problem," Computers and Operations Research, vol. 29, no. 1, pp. 33-51, 2002.

[115] S. W. Lin, V. F. Yu, and S. Y. Chou, "Solving the truck and trailer routing problem based on a simulated annealing heuristic," Computers and Operations Research, vol. 36, no. 5, pp. 16831692, 2009.

[116] S. W. Lin, V. F. Yu, and C. C. Lu, "A simulated annealing heuristic for the truck and trailer routing problem with time windows," Expert Systems with Applications, vol. 38, no. 12, pp. 15244$15252,2011$.

[117] J. G. Villegas, C. Prins, C. Prodhon, A. L. Medaglia, and N. Velasco, "A GRASP with evolutionary path relinking for the truck and trailer routing problem," Computers and Operations Research, vol. 38, no. 9, pp. 1319-1334, 2011.

[118] J. H. Song and K. C. Furman, "A maritime inventory routing problem: practical approach," Computers and Operations Research, vol. 40, no. 3, pp. 657-665, 2013.

[119] Y. Adulyasak, J. F. Cordeau, and R. Jans, "Formulations and branch-and-cut algorithms for multi-vehicle production and inventory routing problems," Tech. Rep. G-2012-14, GERAD, Montreal, Canada, 2012.

[120] L. C. Coelho and G. Laporte, "The exact solution of several classes of inventory-routing problems," Computers \& Operations Research, vol. 40, no. 2, pp. 558-565, 2013.

[121] C. Archetti, L. Bertazzi, G. Laporte, and M. G. Speranza, "A branch-and-cut algorithm for a vendor-managed inventoryrouting problem," Transportation Science, vol. 41, no. 3, pp. 382391, 2007.

[122] J. F. Bard and N. Nananukul, "A branch-and-price algorithm for an integrated production and inventory routing problem," Computers \& Operations Research, vol. 37, no. 12, pp. 2202-2217, 2010.
[123] T. Benoist, F. Gardi, A. Jeanjean, and B. Estellonbertrand, "Randomized local search for real-life inventory routing," Transportation Science, vol. 45, no. 3, pp. 381-398, 2011.

[124] T. F. Abdelmaguid and M. M. Dessouky, "A genetic algorithm approach to the integrated inventory-distribution problem," International Journal of Production Research, vol. 44, no. 21, pp. 4445-4464, 2006.

[125] S. Babaie-Kafaki, R. Ghanbari, S. H. Nasseri, and E. Ardil, "Solving bus terminal location problem using genetic algorithm," World Academy of Science, Engineering and Technology, vol. 14, pp. 764-767, 2008.

[126] R. Grønhaug, M. Christiansen, G. Desaulniers, and J. Desrosiers, "A branch-and-price method for a liquefied natural gas inventory routing problem," Transportation Science, vol. 44, no. 3, pp. 400-415, 2010.

[127] D. Popović, M. Vidović, and G. Radivojević, "Variable neighborhood search heuristic for the inventory routing problem in fuel delivery," Expert Systems with Applications, vol. 39, no. 18, pp. 13390-13398, 2012.

[128] K. L. Hoffman and M. Padberg, "Solving airline crew scheduling problems by branch-and-cut," Management Science, vol. 39, no. 6, pp. 657-682, 1993.

[129] T. Emden-Weinert and M. Proksch, "Best practice simulated annealing for the airline crew scheduling problem," Journal of Heuristics, vol. 5, no. 4, pp. 419-436, 1999.

[130] P. Lucic and D. Teodorovic, "Simulated annealing for the multiobjective aircrew rostering problem," Tech. Rep., Faculty of Transport and Traffic Engineering, University of Belgrade, 1998.

[131] D. Levine, "Application of a hybrid genetic algorithm to airline crew scheduling," Computers and Operations Research, vol. 23, no. 6, pp. 547-558, 1996.

[132] C. L. Huntley, D. E. Brown, D. E. Sappington, and B. P. Markowics, "Freight routing and scheduling at CSX transportation," Interfaces, vol. 25, no. 3, pp. 58-71, 1995.

[133] V. Salim and X. Cai, "A genetic algorithm for railway scheduling with environmental considerations," Environmental Modelling and Software, vol. 12, no. 4, pp. 301-309, 1997.

[134] K. Nachtigall and S. Voget, "A genetic algorithm approach to periodic railway synchronization," Computers and Operations Research, vol. 23, no. 5, pp. 453-463, 1996.

[135] L. Ping, N. Axin, J. Limin, and W. Fuzhang, "Study on intelligent train dispatching," in Proceedings of the 2001 IEEE Intelligent Transportation Systems, pp. 949-953, Oakland, Calif, USA, August 2001.

[136] S. Wegele and E. Schnieder, "Dispatching of train operations using genetic algorithms," in Proceedings of the 9th International Conference on Computer-Aided Scheduling of Public Transport (CASPT '04), San Diego, Calif, USA, 2004.

[137] M. Yaghini, A. Foroughi, and B. Nadjari, "Solving railroad blocking problem using ant colony optimization algorithm," Applied Mathematical Modelling, vol. 35, no. 12, pp. 5579-5591, 2011.

[138] Y. Yue, L. Zhou, Q. Yue, and Z. Fan, "Multi-route railroad blocking problem by improved model and ant colony algorithm in real world," Computers and Industrial Engineering, vol. 60, no. 1, pp. 34-42, 2011.

[139] A. Arias-Montano, C. A. C. Coello, and E. Mezura-Montes, "Multiobjective evolutionary algorithms in aeronautical and aerospace engineering," IEEE Transactions on Evolutionary Computation, vol. 16, no. 5, pp. 662-694, 2012. 
[140] R. Salim and M. Bettayeb, " $H_{2}$ and $H_{\infty}$ optimal model reduction using genetic algorithms," Journal of the Franklin Institute, vol. 348, no. 7, pp. 1177-1191, 2011.

[141] P. Schittekat, J. Kinable, K. Sörensen, M. Sevaux, F. Spieksma, and J. Springael, "A metaheuristic for the school bus routing problem with bus stop selection," European Journal of Operational Research, vol. 229, no. 2, pp. 518-528, 2013.

[142] J. Euchi and R. Mraihi, "The urban bus routing problem in the Tunisian case by the hybrid artificial ant colony algorithm," Swarm and Evolutionary Computation, vol. 2, pp. 15-24, 2012.

[143] J. Park, H. Tae, and B. I. Kim, "A post-improvement procedure for the mixed load school bus routing problem," European Journal of Operational Research, vol. 217, no. 1, pp. 204-213, 2012.

[144] J. Pacheco, R. Caballero, M. Laguna, and J. Molina, "Bi-objective bus routing: an application to school buses in rural areas," Transportation Science, vol. 47, no. 3, pp. 397-411, 2013.

[145] J. Riera-Ledesma and J. J. Salazar-González, "A column generation approach for a school bus routing problem with resource constraints," Computers \& Operations Research, vol. 40, no. 2, pp. 566-583, 2013. 


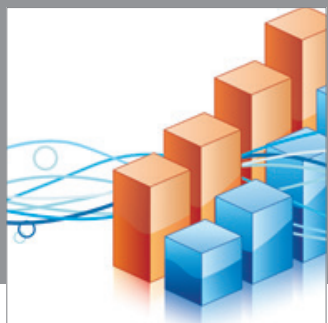

Advances in

Operations Research

mansans

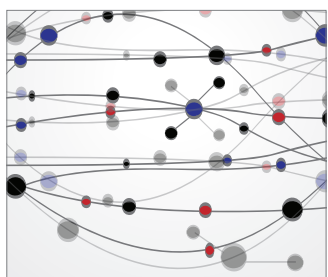

The Scientific World Journal
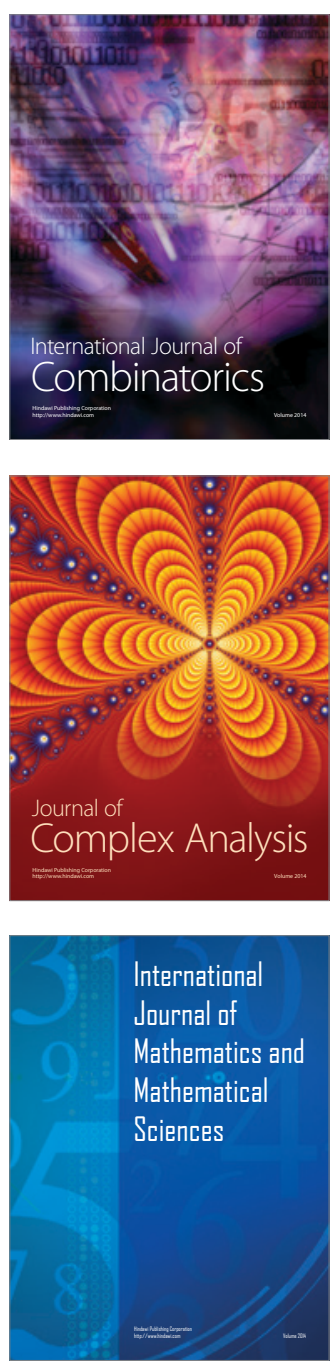
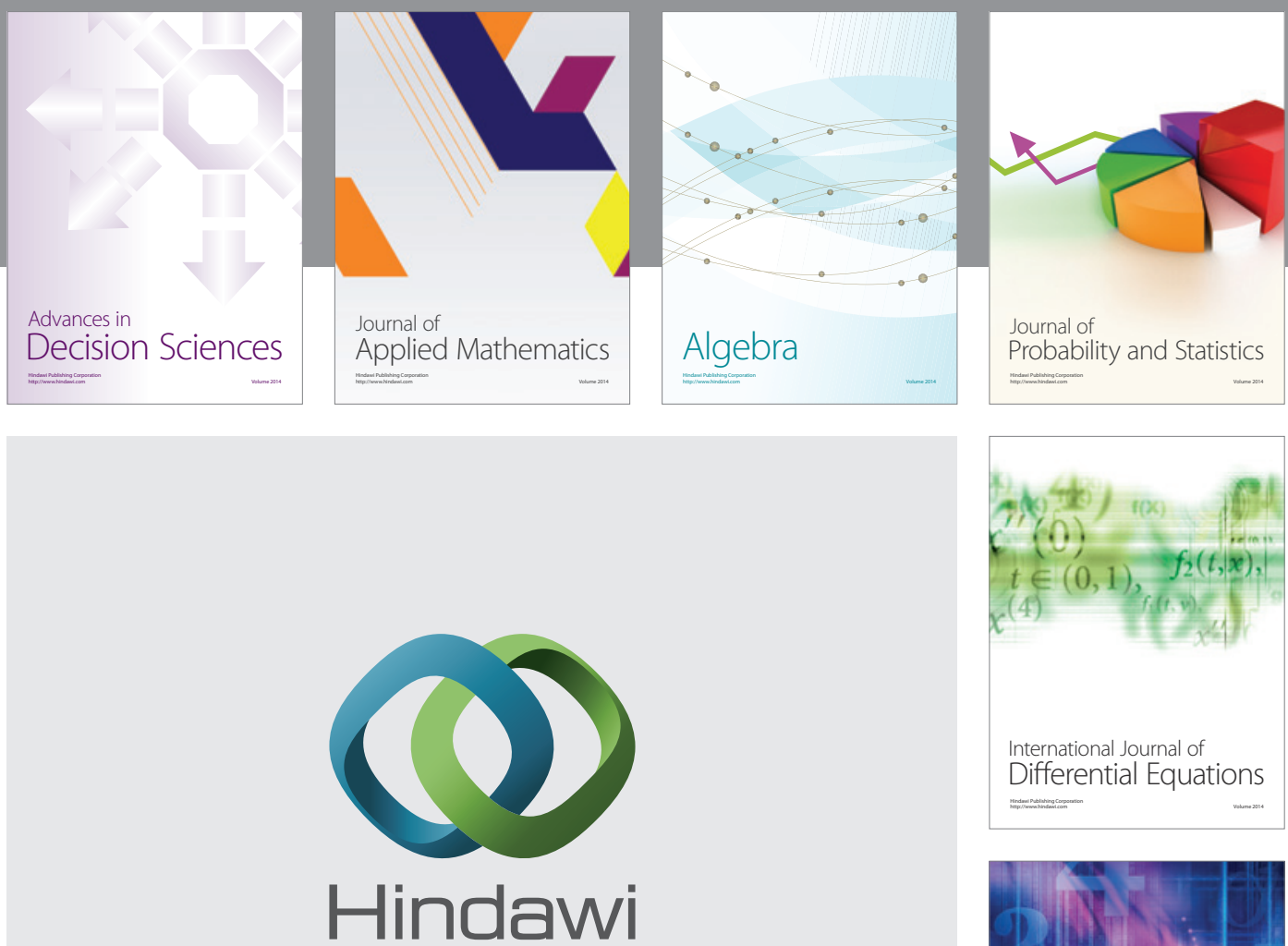

Submit your manuscripts at http://www.hindawi.com
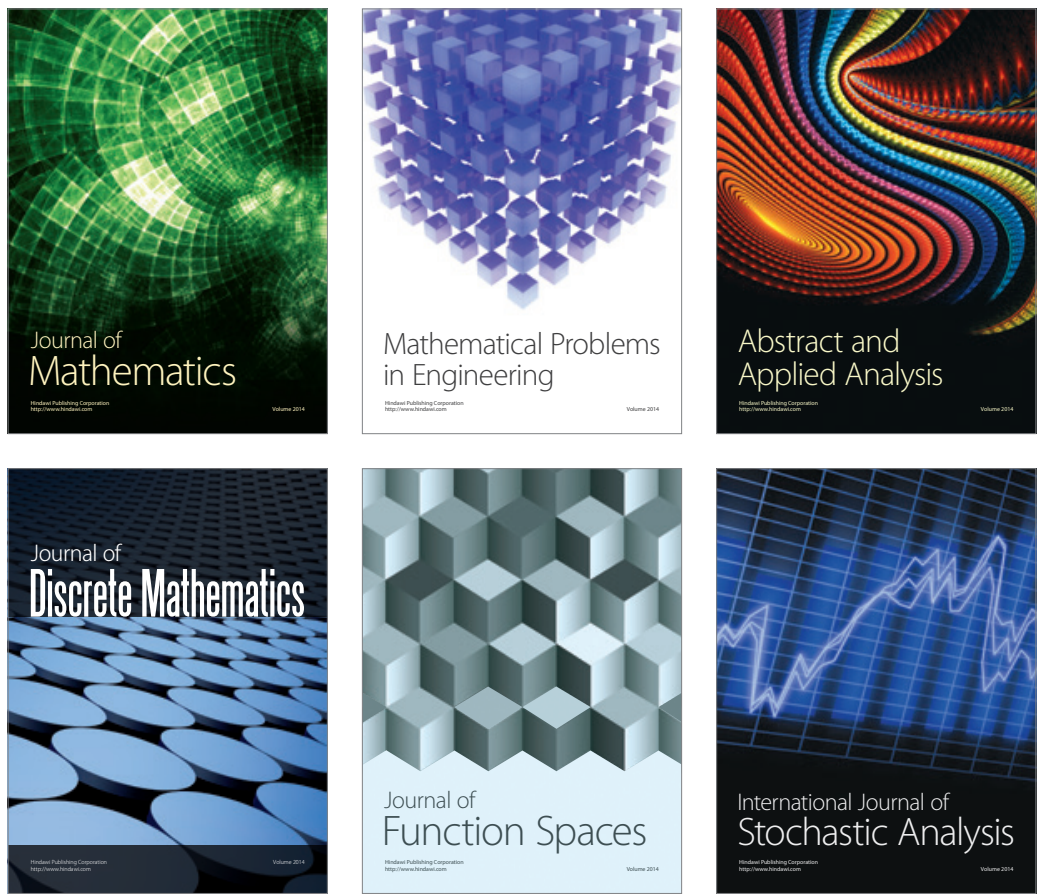

Journal of

Function Spaces

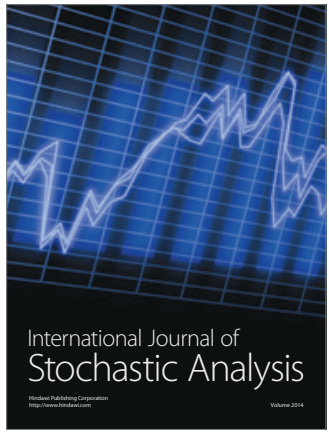

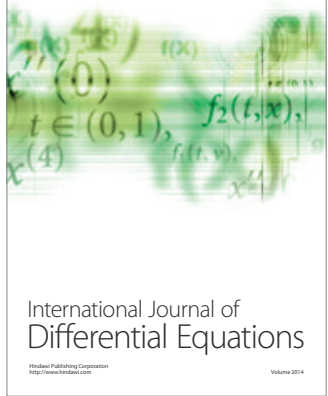
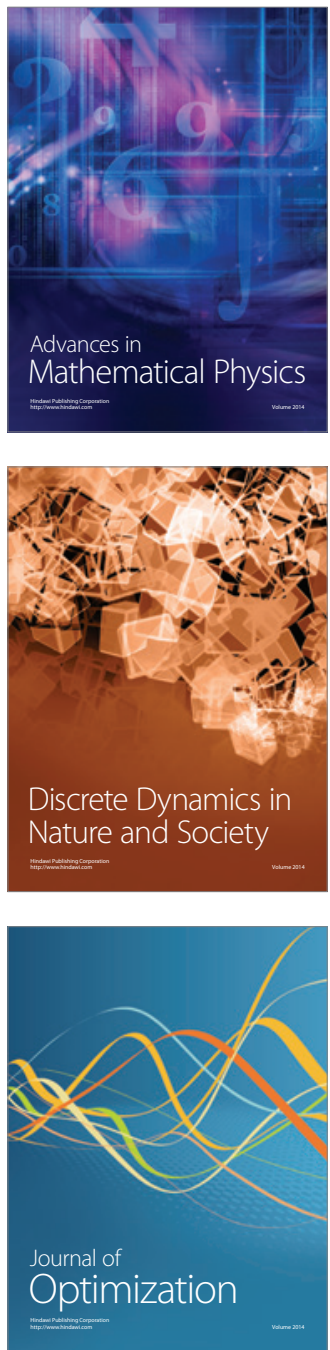